\title{
CONSTRUCTION AND CALCULATION OF ABSOLUTE STANDARDS OF INDUCTANCE.
}

\author{
By J. G. Coffin.
}

PART I. Construction and Measurement of the Standards.
I. Introduction.
2. The Advantages of Marble.
3. The Grinding Machine.
4. Shaping the Marble Cylinders.
5. Measuring the Cylinders.
6. Results of the Measurements.
7. Winding the Coils.
8. Axial Length of the Windings.

PART II. Theory of the Calculation of Standards of Mutual and Self Inductance.

I. Method I. Self-inductance by Summation of a Finite Series.

2. Method II. Self-inductance by Converging Infinite Series.

3. Method III. Self-inductance in Terms of Elliptic Integrals. Exact Formula.

4. Method IV. Mutual and Self Inductance. Kirchhoff's Formula.

5. Method V. Mutual Inductance. Maxwell's Formula.

6. Method VI. Mutual Inductance. Ròiti's Formula.

7. Data for Calculation. Bureau of Standards Coil.

8. Clark University Coil.

9. Temperature Coefficient of the Inductance Standards.

Io. On the Distributed Capacity of a Coil.

II. Effects of Deviations from the Mean Radius.

PART I.

CONSTRUCTION AND MEASUREMENT OF THE STANDARDS.

\section{INTRODUCTION.}

The work of this paper was undertaken with a view to the construction and calculation of a primary standard of self-inductance for the Bureau of Standards and of one for the Physical Laboratory of 
Clark University, Worcester, Mass. It is hoped that the following account of the theory and methods of construction will direct the way and materially decrease the labor of any future undertakings of a similar character. Very little is to be found anywhere on the precautions to be taken in very precise work of this kind, and there were but few formulæ accurate enough for the calculation of the completed standard in absolute measure. It is hoped that the present paper will to some extent fill this lacuna in the literature of the subject.

The construction of a standard of inductance involves many considerations. A primary standard need not necessarily be of a convenient size or weight for ordinary use, but on the other hand it should not be too difficult to manage under favorable circumstances. A standard of any kind should have as nearly as possible the characteristics and properties which are required of standards of length and mass-i. e., as nearly as possible unalterability with age, convenient electrical magnitude for practical measurement, and furthermore all dimensions should be readily determinable to the required degree of accuracy and redeterminable at any time. A convenience which is desirable, but not always attained, is the facility of comparing the standard with one or more of its own subdivisions, thus checking calculated values in terms of itself. This has been made possible in the present instance, as will be explained below.

There are several materials available for forms for standard coils, each with certain advantages and disadvantages. Metal, wood, glass, plaster of Paris, and other compositions were all considered.

Wood has been used for standard inductances and has the advantage of lightness and cheapness, but has also the absolutely prohibitive fault of being liable to warp, however well seasoned and well constructed. Metals must be barred out because of eddy currents which render the value of the inductance a function of the periodicity. Metal forms are also hard to obtain without strains and are very liable to suffer distortion while being worked. Glass and plaster of Paris are excellent materials for coils of small size. Plaster of Paris soaked in paraffin has been tried and found to answer very well, but is more liable to injury than marble, is less rigid, and can not be ground as true. For large coils, glass would be very expensive, and although cost should not be the determining factor in the construction of 
primary standards it nevertheless must be considered. Glass in such large masses would also be very difficult to obtain. The material chosen for this coil was marble.

\section{THE ADVANTAGES OF MARBLE.}

The advantages of marble are manifest. It is comparatively inexpensive and easy to obtain in almost any shape or size. It is unalterable and not attacked by moisture or air, as shown by the marvelous preservation of temples and statues of ancient Greece and Rome, which have stood the test of centuries both underground and exposed to the elements. Its electrical resistance is very high, some samples having a value as high as that of hard rubber. In ordinary work it is feasible to wind bare wire directly on the marble. The coefficient of magnetic susceptibility of marble is very small, and is negative for all kinds investigated; in other words, marble is diamagnetic. The work of A. P. Wills ${ }^{1}$ shows that almost any variety of marble can be relied upon to be free from iron and to have a magnetic susceptibility of about $-0.8 \times 10^{-6}$.

The following values are taken from Wills's paper:

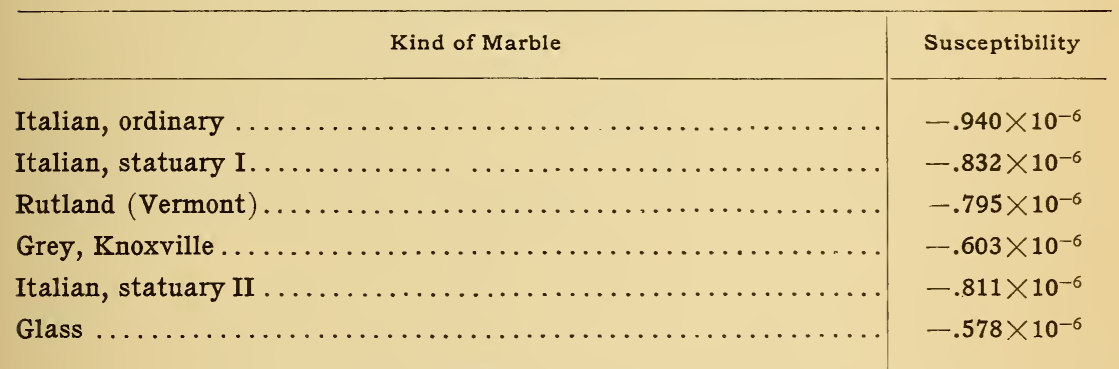

To avoid any uncertainty, it was thought best to determine the coefficient of susceptibility of samples of the marble from which the cylinders had been cut. Pieces were taken from the cores of the cylinders and their susceptibility measured by the method of A. P. Wills, the work being done by Mr. G. E. Stebbins, a fellow of Clark University, to whom I am indebted for the following results:

For sample of Coil I, $\kappa=-0.986 \times$ IO $^{-6}$

For sample of Coil II, $\kappa=-0.968 \times$ IO $^{-6}$

\footnotetext{
${ }^{1}$ On the Susceptibility of Diamagnetic and Weakly Magnetic Substances, Physical Review, 6, No. 33, April, I8g8.
} 
From these values, which agree very closely with the values found by Wills for Italian marble, it is found that for both $\mu=.999988$. Thus if all the space about the coil were filled with marble like the sample the inductance would be altered by about one part in I00,000. But only part of the air space is replaced by the marble and less than half of the magnetic lines go through the material; hence the effect of the small departure of $\mu$ from unity amounts to only a few parts in a million and is absolutely negligible.

The density of the marble is about 2.74, and its coefficient of linear expansion is about 0.0000 ro per degree centigrade, or about half that of brass.

\section{THE GRINDING MACHINE.}

The marble dealers ${ }^{1}$ delivered the cylinders accurate to an eighth or a sixteenth of an inch. The dimensions chosen for these standards were such as to give an inductance of about 0.2 henry. For theoretical reasons the length of the coil was made equal to the radius multiplied by $\sqrt{3}$. This made the dianeter about $54 \mathrm{~cm}$ and the length covered with wire about $46 \mathrm{~cm}$, the total length of the marble cylinder being about $5 \mathrm{I} \mathrm{cm}$; the thickness of the hollow cylinder after the core was removed was about II $\mathrm{cm}$. It is thus seen that the size and weight are not inconsiderable. The only machine in Worcester capable of grinding such a cylinder was the Poole grinder of the Rice, Barton \& Fales Company.

The inductance coil consists of a single layer of wire wound on as nearly a perfect circular cylinder of marble as it is possible to produce. Every turn of wire is thus open for inspection; and there is very little electrostatic capacity. In fact, with such a coil the capacity is smaller than for any other coil of the same inductance. A circular cylinder, determined by two dimensions only, is the easiest figure to obtain perfect. The wire was of such a size as to give about I 5 or 16 turns to the centimeter. With such a small pitch, it is evident that a very close approximation is made to the mathematical fiction of a cylindrical current sheet.

Cylinders of a diameter less than $45 \mathrm{~cm}$ can be ground also on the Norton $^{2}$ grinder, although I have had no experience with cylinders 
of such large size on this machine. An accuracy of from I/ 5000 to I. IOOOO of an inch can be obtained on small work (say from $20 \mathrm{~cm}$ down) both in steel and brass. The great advantage of this machine is that the work can be revolved on centers, which is the most accurate of all methods. The disadvantage is that the precision of the work depends upon the straightness of the ways along which the grinding tool runs.

The Poole grinder is used to grind the rolls or calenders employed in paper machinery. It will grind cylinders up to $7 \mathrm{I} \mathrm{cm}$ in diameter and over three meters in length, the limit in weight being about ten tons. On this grinder the cylinder being ground does not revolve on centers, but the shaft turns on bearings provided with three points of contact. It was therefore necessary to have a shaft whose bearings could be ground true on centers. This was done by the Norton Emery Wheel Company, of Worcester, Mass. The dimensions of the shaft were such that the sag of the shaft and marble when supported on its ends would produce no noticeable error in the diameter while being ground.

The deflection of a beam of circular cross section loaded at the center with a weight $W$ is

$$
\delta=\frac{W l^{3}}{48 E I}
$$

If uniformly loaded with weight $w$ per unit of length it is

$$
\delta=\frac{5 w l^{4}}{384 E I}
$$

where $I$ is the moment of inertia of the cross section, $E$ Young's modulus of elasticity, and $l$ the length between supports.

Calculating by both formulæ and adding, it was found that a shaft Io $\mathrm{cm}$ in diameter would deflect less than $0.025 \mathrm{~cm}$, while with I $2.7 \mathrm{~cm}$ diameter the deflection would be only about $0.0 \mathrm{~cm}$. The deflection is actually much less than this, as all weights were less than those used in the calculation. The system of marble and steel was much stiffer than the simple steel shaft and the points of support nearer together than in the calculation. Besides, the bending of the shaft produces an error of the second order only, as the change in diameter of a cylinder between grinding wheels of constant distance apart, due to a sag of $0.0 \mathrm{~cm}$, is very small indeed, being about one part in a million for a cylinder of $25 \mathrm{~cm}$ radius. 


\section{SHAPING THE MARBLE CYLINDERS.}

Figure I shows the shaft with marble cylinder mounted, the total weight being in the neighborhood of three-quarters of a ton.

The Poole grinder is of special interest because in grinds the work round and makes the sides parallel, to a great extent independently of the ways on which the grinding wheels are carried. Two emery wheels are rigidly connected together, one on each side of the marble cylinder, so that as they grind at opposite ends of a diameter they practically form a grinding caliper. The cylinder, or "roll," is rotated on journals, which remain in position during the whole process. It is the system of grinding wheels which is carried back and forth on $45^{\circ}$ angled ways.

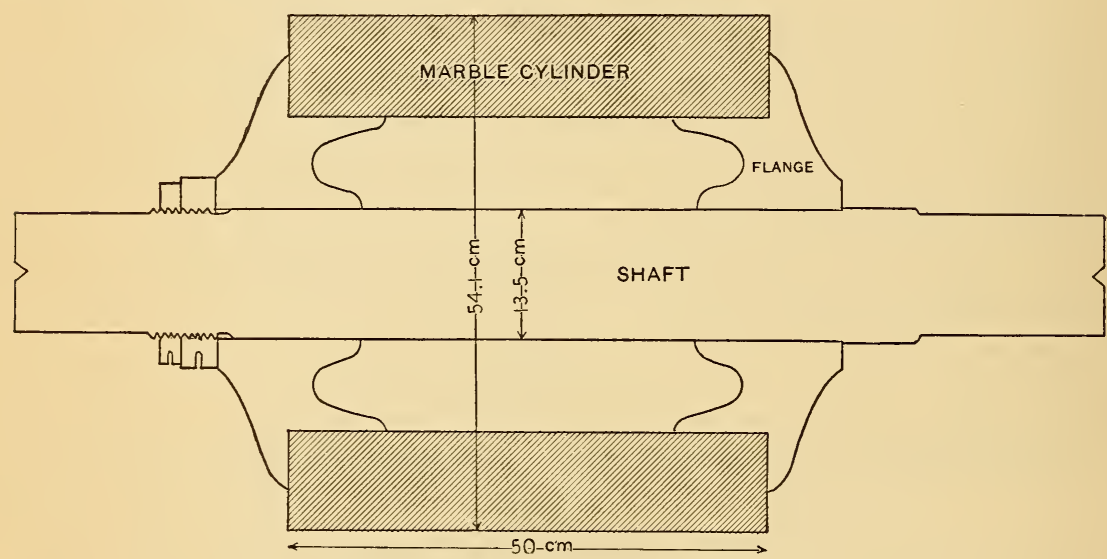

Fig. 1.-Section of Shaft and Marble Cylinder Mounted.

Consideration of this arrangement shows that if the two grinders act evenly and alike from one end of the roll to the other, which condition is indicated by the sound of the grinding, the roll must be round, and at the worst slightly conical. A cone is ground whenever the axis of the shaft of the roll is not parallel with the plane of the two ways upon which the grinding bed slides. By making this adjustment even roughly we may be sure of obtaining a practically true cylinder independently of variations in the ways, and even of the trueness of the shaft bearings.

A stream of water is continually flowing over the cylinder so that the heating effect at the grinding area is practically eliminated. 
The grinders revolve at about 2,0oo revolutions per minute. No pains were spared in the adjustments of the grinder to make all as nearly perfect as possible. It is easy to tell by the sound whether the emery wheels are grinding evenly or not. The amount of stock that is ground off in a single traverse is very small, not more than a thousandth of an inch. When the roll is considered nearly finished the distance between the wheels is not altered, and they are allowed to grind back and forth several times in this manner. It is not advisable to continue this process too long, as, when the wheels have no stock to grind, what is technically known as "pounding" ensues, i. e., the emery wheels rebound back and forth, cutting depressions in the marble. The grinding wheels are connected to a mass weighing about two tons, the whole suspended on knife edges, but so sensitively balanced that a slight pressure of the finger will move them.

The finished surface is smooth, bright, and almost polished, except for small scratches here and there, due to a loosening of emery particles from the wheels. No difference could be detected between any two diameters, with the cathetometer used horizontally, in the preliminary measurements. A second cylinder ground subsequently on this same machine was ground to a given diameter, as nearly as possible to within a few thousandths of an inch of the length of the end standard by which it was measured.

\section{MEASURING THE CYLINDERS.}

After grinding, the cylinders were transferred to the machine shop of the department of physics, Clark University, and all subsequent operations were carried on there.

A sketch of the shaft used, with the cast-iron flanged supporting disks, is shown in Fig. I. The dimensions were such that the sag under the actual load produced no appreciable error in the grinding. It is necessary to protect the iron surface in contact with the marble with tallow, otherwise the rust will bind the two surfaces so tightly that they are separated only with great difficulty.

The measuring apparatus shown in Fig. 2 was devised so as to afford an easy method for verifying the accuracy of the cylinder. It consists of a heavy iron girder $A B$ to which two brass pieces $C$ and $D$ are screwed. These brass pieces formed part of a geometri- 
cal hinge. From these pieces hang two very stiff bars $C F$ and $D E$. These bars may be taken down by pulling out two accurately ground steel rods $C$ and $D$, which, passing through two triangular holes in the brass parts of the hinge, form a geometrical clamp.

The lower ends of the vertical bars were joined by a brass connecting rod $E F$, freely movable about axes through $E$ and $F$. The system thus described forms a jointed parallelogram. The size was such as to allow about one-fourth inch clearance between the vertical bars and the cylinder when the latter was in place. Near the middle of one of the bars $C F$ was placed a Brown \& Sharpe 0.5 $\mathrm{mm}$ micrometer screw with a large head graduated into Ioo parts.

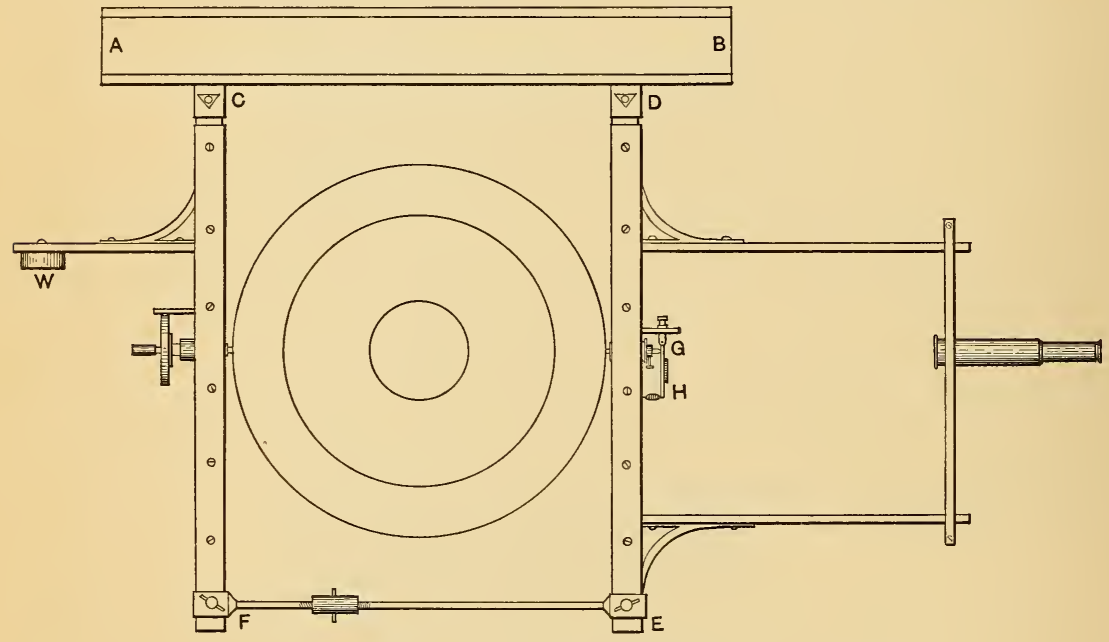

Fig. 2.-Measuring Apparatus.

Opposite, on the other bar, was placed a steel plunger, which was lightly pressed against the cylinder by means of a spring. The steel contact pieces were hardened, ground, and polished spherical.

The other end of the plunger (see Fig. 3) touches a steel lever very near to its axis of rotation. This lever is gently held against the plunger by a very light spring, and on the lever is placed a plane mirror GH. Built out from the bar is a telescope and scale attachment, by means of which any angular motion of the lever relative to the bar may be accurately read to one-tenth of a scale division.

The mean of four settings with this arrangement always agreed to within one ten-thousandth $\mathrm{mm}$. 
To calibrate the apparatus at any time, all that is necessary is to turn the micrometer screw through a given amount and note the readings. The multiplication was generally such that one scale division indicated about $0.0003 \mathrm{~cm}$. A weight $w$ was placed on the other bar to compensate for the weight of the telescope, etc. If now the cylinder be placed in position inside of this caliper system and turned, any variation in diameter may be observed and measured.

Bearings of hard wood were built up from the platen of a planer, and the cylinder and shaft rested on these. By means of a crank screwed to one end of the shaft the marble cylinder could be turned on its axis, and it could be moved back and forth by means of the planer. Adjustments were made once for all, so that the axis of the shaft, and therefore of the cylinder, was parallel with the ways of the planer. This could be done by trial to about $0.3 \mathrm{~mm}$. A scaffolding was built up from the floor to support the measuring apparatus, so that no jarring due to motion of the cylinder could be transmitted to the frame.

It is desirable to be able to start and stop the heavy mass with small effort and without any trembling of the bed. Mutton tallow accomplishes this result, when using wood bearings, better than any other lubri-

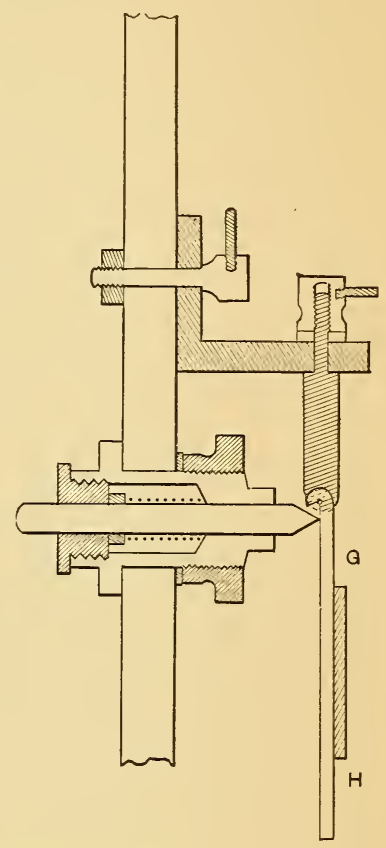

Fig. 3.-Plunger and Details of Measuring Apparatus. cant. Heavy oils ooze out, although while the cylinder is in rotation they lubricate well.

The cylinder before being set up for measurement was put in a lathe and nineteen circles I inch apart were drawn in pencil on the surface. Sixteen equidistant generators were also drawn, so that the whole surface was mapped out by a system of cylindrical coordinates. In measuring the diameters of any circular section, the cylinder was turned once around, thus giving two measures of each diameter; if these did not closely agree the section was remeasured. A number of surveys involving thousands of observations were madé. 
The mean results are here plotted and show the remarkable perfection of the cylinders. It is probably the nearest approach to the perfect cylinder, for its size, which exists. No variation over $0.0013 \mathrm{~cm}$ occurs.

A particular diameter was now chosen near one end as a standard and all others referred to it. The Bureau of Standards furnished a measured steel end standard about $54 . \mathrm{I} \mathrm{cm}$ long. This bar had spherical ends, the curvature being such that the bar was a diameter of the sphere of which they form a part. This construction allows of small angular displacements of the bar without sensibly changing its length. A series of comparisons between the bar and the standard diameter on the cylinder showed an average difference of only .ooor I mm. The arithmetical mean of all the diameters was now taken, giving as a result:

Mean diameter of bare cylinder=length of the standard bar + . OI $355 \mathrm{~cm}$.

By a consideration of the plots of the variations in diameter along generators the mean circular section could be picked out, and by a consideration of the different diameters of this mean circular section a mean diameter could be deduced. This last estimate is entirely independent of the first value deduced by taking the arithmetical mean. The two results, however, agreed to within $.00004 \mathrm{~cm}$. This is a variation of less than I in I,000,000. It may, therefore, safely be said that the mean diameter is correct to I part in 50,000, and probably to within I part in I00,000. Two holes were bored into the ends of the marble $\mathrm{I} 80^{\circ}$ apart and parallel to the axis; these holes were $\mathrm{I} 2 \mathrm{in}$. deep, so that the temperature of the marble may be accurately determined by lowering thermometers into them. The thermometers used were all compared over a large range with a standard thermometer of Baudin, calibrated by the Bureau International at Sèvres. Holes were now bored radially through the marble, all cutting one and the same generator, and hard rubber plugs fitted in them. Measurements showed that their surfaces could be made practically continuous with the marble surface. A rough calculation will show that even were they out by a tenth of a millimeter the effect on the mean radius is infinitesimal. 


\section{RESULTS OF THE MEASUREMENTS.}

The means of several series of measurements were plotted, and two samples of such are given below. The first (Fig. 4) shows the variations in diameter of the University coil on different circular sections, as the cylinder is turned. The sections near the ends show more variations than any other; this is due to inequalities in grinding as the wheels leave the surface at these points. The section marked

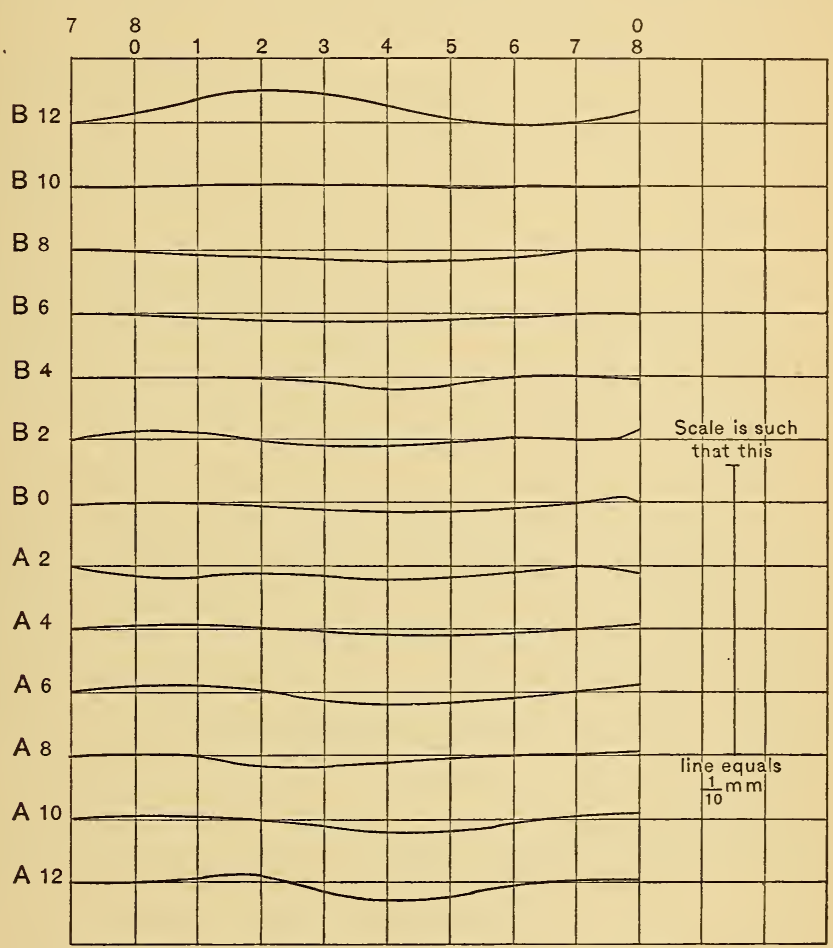

Fig. 4.-Diagrams Showing Variations in Diameters of a Number of Equidistant Circular Sections of the University Cylinder. (Abscissa 7 is an Arbitrary Zero).

$\mathrm{B}$ Io happens to be so nearly circular that it is almost impossible to see any variation at all. The inequalities there are about o.oooI $\mathrm{mm}$. These curves have no relation to one another, but are all referred to an arbitrary zero, along generator 7 . Fig. 5 shows the variations of diameter along different generators, as one goes from end to end, of the coil of the Bureau of Standards. The scale is such that each division is equivalent to o.or $\mathrm{mm}$. These curves are 
not independent, but show the actual relative position of every point on the cylinder, any one point being taken as an arbitrary zero.

The cylinder is seen to be on the whole very slightly conical, the amount, however, being very small, as the maximum variation is only $0.013 \mathrm{~mm}$ and the mean variation only about $0.005 \mathrm{~mm}$.

The actual mean radius in terms of the standard is determined to a far greater accuracy than this, better, in fact, than the length of the end standard is known. The similarity of the different curves to each other shows that the cylinder is very nearly round. A plot of the variations in diameter on circular sections can easily be made by plotting the eight values, found by reading up and down on Fig. 5.

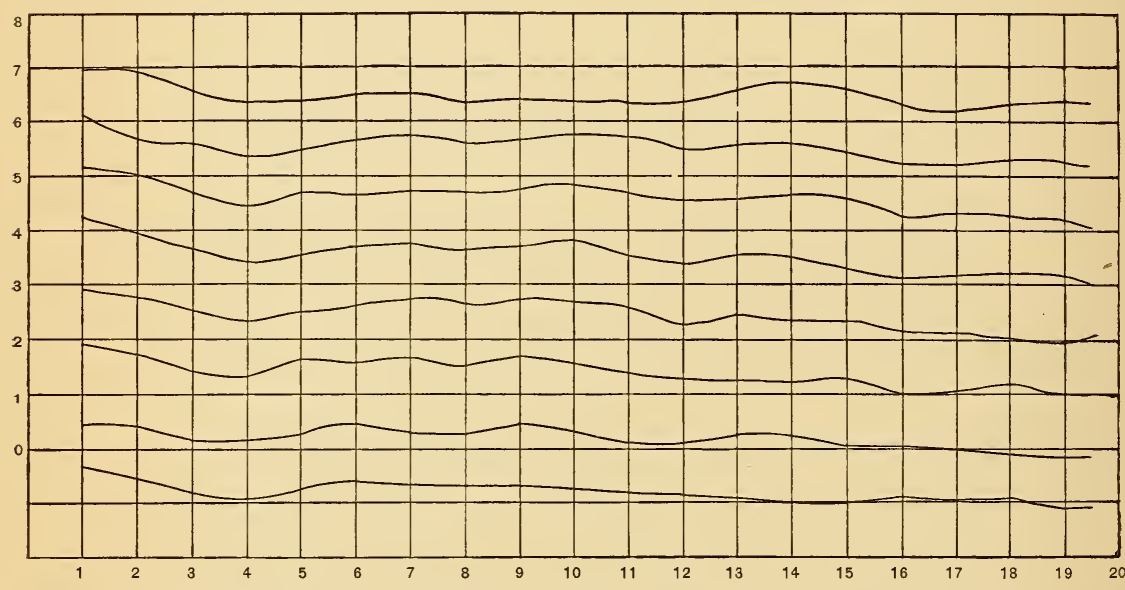

Fig. 5.-Diagrams Showing Variations in Diameters of Bureau of Standards Cylinder. Each Space Represents $0.01 \mathrm{~mm}$. The Mean Variation of All the Diameters is One-half a Space, or $0.005 \mathrm{~mm}$.

To estimate the accuracy of the wound coil numerous measurements of the variations in diameter of the completed coil were made. The variations were all under o.or $\mathrm{mm}$. The axis of the wire has therefore less variation than this, as the above value, o.or $\mathrm{mm}$, is due to the inequalities of four thicknesses of insulation, while the variation in the axis is only due to two.

The winding was accomplished on warm days, so that as the coil is generally at a lower temperature than that at which it was wound, the greater contraction of the copper wire over that of the marble would tighten rather than loosen it. 
The length of the standard bar furnished by the Bureau of Standards at $24.2 \mathrm{I}^{\circ} \mathrm{C}$ is $54 . \mathrm{II} 40 \pm .0005 \mathrm{~cm}$. Its coefficient of expansion is $0.0000 \mathrm{II}$. The measurements showed that the mean diameter of the cylinder equals the length of the standard bar minus 0.00892 $\mathrm{cm}$, the bar being at $\mathrm{I} 7.50^{\circ} \mathrm{C}$ and the cylinder at $\mathrm{I} 6.4 \mathrm{I}^{\circ} \mathrm{C}$. Taking the coefficient of expansion of marble to be o.ooooro (the mean of all available values for Italian marble), we find the mean diameter of the marble cylinder at $20^{\circ} \mathrm{C}$ as follows:

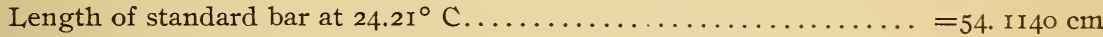

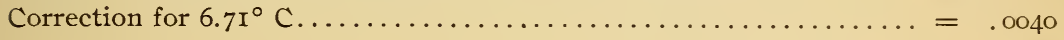

Length of standard bar at $17.50^{\circ} \mathrm{C} \ldots \ldots \ldots \ldots \ldots \ldots \ldots \ldots \ldots \ldots \ldots \ldots \ldots \ldots \ldots$

Deduct difference between diameter of cylinder and length of bar... = . oo89

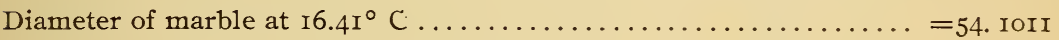

Correction for $3.6^{\circ} \mathrm{C},=36$ parts in a million $\ldots \ldots \ldots \ldots \ldots \ldots \ldots \ldots \ldots \ldots \ldots$. oorg

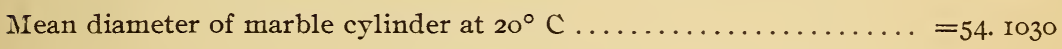

\section{WINDING THE COILS.}

The two coils differ only in detail. In what follows the first of two values refers to the coil at Washington and the second to the coil at Clark University. The wires used are such that when wound on the cylinder there were 36.6 and $4 \mathrm{r} .25$ turns to an inch. These correspond to diameters of $0.0695 \mathrm{~cm}$ and $0.06 \mathrm{I} 7 \mathrm{~cm}$, respectively. The thicknesses of the insulations are very small, being only 0.0030 $\mathrm{cm}$ and $0.0008 \mathrm{~cm}$ for the two coils, respectively. The wire was made expressly for this work by the General Electric Company, being drawn through a diamond die, special precautions being taken to insure a uniform thickness of insulation.

The insulation goes by the name of "Enamel," and is ideal for the present purpose. As nothing could be assumed about its insulation resistance it was necessary to measure it. Ordinary methods of insulation resistance measurements could not be used, as the insulation contained many microscopic faults which, although producing no bad effect when used dry in the ordinary manner, allowed a current to flow through the insulation into the salt water used in the test.

It was finally decided to wind two wires at a time on the University coil, so that in reality the cylinder is covered by two separate 
helices of wire, every turn of one being between turns of the other, except at the ends. Measuring the resistance between the two helices the insulation resistance of the wire in place is found. This turned out to be very high, about 30 or 40 megohms between two half-mile lengths of wire in intimate contact.

Just before winding, the surface of the marble was rubbed with a solution of paraffin in turpentine to clean it and increase the surface insulation.

The wire was wound single on the Bureau of Standards coil, but the winding was subdivided into three parts, thus allowing many combinations. The insulation on the wire of this latter coil being nearly four times thicker than on the

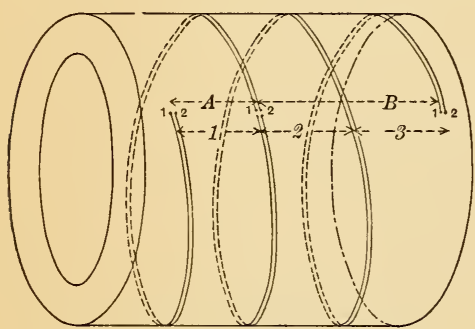

Fig. 6.-Scheme of Winding. other coil, it was thought unnecessary to wind it double, in order to test its insulating properties.

The scheme of winding is easily understood from the diagram, Fig. 6. To guide the wire at the start a long strip of paper was glued around the end of the marble, about seven or eight layers giving a sufficient thickness. The inside edge was now trimmed with a special tool, the cylinder being turned on its own axis. In the University coil two strands were wound on at once, and the windings were pressed close together during the process. A uniform tension was mechanically maintained on the wire. The windings remained parallel to the original ones, so that after six or seven hundred turns they coincided almost exactly with the rim at the other end.

The wires go through the marble in the center of the plugs and immediately return through the same holes. This allows the coil to be subdivided and yet does not impair the uniformity of the winding; indeed it is difficult to find the spots in question where this division takes place.

In the University coil, in which the winding is double, there are in reality four separate and distinct coils alike in pairs. The terminals to these four coils are brought up to a hard rubber plug near one end of the cylinder on the inside. The wiring on the inside is 
right-angled, so that the inductances of these portions may be calculated and added to the total. They are, however, very small. It is thus seen that any combination of the four coils may be made, the current flowing in either direction in any section. This gives a large number of different substandards whose values are calculable.

A standard of mutual inductance is also furnished by this coil, since if the self-inductance of the whole coil is known, as well as of the smaller coils. the following relation holds:

$$
L_{1+2}=L_{1}+2 M_{12}+L_{2}
$$

from which $M_{12}$ may be calculated.

The coil in the possession of the Bureau of Standards is subdivided into three smaller coils all unequal. Calling these coils I, 2, and 3 , the following values have been calculated:

$$
\begin{array}{lll}
L_{1} & L_{(1+2)} & L_{(1+2+3)} \\
L_{2} & L_{(2+3)} & \\
L_{3} . &
\end{array}
$$

From which may be derived the following:

$$
\begin{array}{lll}
L_{1+3} & L_{1-2} & L_{2-3} \\
L_{1-3} & L_{1+2-3} & L_{1-2+3} \\
L_{-1+2+3} & M_{12} & M_{23} \\
M_{13} & M_{(1+2) 3} & M_{1(2+3)}, \text { and others. }
\end{array}
$$

The ratios of the calculated values may be checked experimentally by the following process. Measure the self-inductance of two adjoining coils (I) when the current is flowing in the same direction in both, and (2) when it is flowing in opposite directions. This measurement may be made in terms of any arbitrary unit.

This first measurement will give-

and the second

$$
L_{A}+2 M_{A B}+L_{B}=L_{S}=L_{A+B}
$$

$$
L_{A}-2 M_{A B}+L_{B}=L_{O}=L_{A-B}
$$

where $L_{A}$ and $L_{B}$ are the self-inductances of the two coils and $M_{A B}$ their mutual inductance, and where $L_{S}$ and $L_{O}$ denote the results of the measurements when the current is flowing in the same direction 
in both and in opposite directions, respectively. We may derive from these equations the following:

$$
\frac{2 M_{\mathrm{AB}}}{L_{\mathrm{A}}+L_{\mathrm{B}}}=\frac{L_{\mathrm{s}}-L_{\mathrm{O}}}{L_{\mathrm{s}}+L_{\mathrm{o}}}
$$

the first ratio is a calculated one, while the second is an experimental one, independent of the unit used.

In a similar manner the ratio of $L_{A}$ to $L_{B}$ may be experimentally tested.

\section{AXIAL LENGTH OF THE WINDINGS.}

The axial length of the windings was measured by means of a Fuess cathetometer fitted with a micrometer microscope, the cylinder being placed on end. The cathetometer was movable about its own axis and a standard meter bar of the Société Genevoise was placed so that by a slight turning of the axis the bar was brought into the field of view. To make sure that any differences in focus might not affect the measurements the micrometer was calibrated at every reading.

As the last turns of wire were so close to the guiding rims that they could not conveniently be observed, readings were taken at noted wires near the ends and also at the windings between the separate coils into which the total coil was divided, settings being made on a fine German silver wire laid in the grooves between adjacent wires. The total number of turns being known, the total length of wire could easily be calculated. The readings were taken along sixteen different generators of the cylinder. The lengths of the subdivisions were determined with about the same absolute deviation as the total length. The wire was calipered with a Brown \& Sharpe wire gauge while being wound on the cylinder. The insulation being hard enamel it was assumed not to be compressed by the tension of the wire against the marble. The diameter of the wire, as calculated from the length measurements, came out smaller than the gauge measurements, which means that the wire stretched slightly while being laid on. The computed value of the diameter of the wire is used in the calculations.

The meter bar of the Société Genevoise, used in the measurements on the University coil, had been calibrated at the Bureau of Standards for its total length, but not for fractions of its length. To verify the 
calibration and obtain corrections for the fractional parts which were used to ineasure the length of the coil, the bar was compared with a ro $\mathrm{cm}$ nickel-steel standard. This standard was furnished by the Bureau International des Poids et Mesures at Sèvres, and had such a table of corrections that any fraction of its length was completely defined. The calibration agreed to within about $5 \mu$ with that of the Burean of Standards, and furnished corrections as reliable as that for the fractional parts required. The mean coefficient of expansion used was:

$$
a_{\mathrm{t}}=\mathrm{IO}^{-8}(\mathrm{I} 844.2+0.66 t) \text { per degree centigrade, }
$$

which was the mean of three similar meter bars calibrated and used by the Bureau International at Sèvres, these three agreeing very closely with each other.

The coil furnished to the Bureau of Standards was measured with a meter bar of the Société Genevoise, which was directly compared with a similar one whose corrections were recently furnished by the Bureau of Standards. The corrections obtained by this calibration were very small. In other words, the two meter bars were nearly identical.

Denoting the subdivisions into which the total coil was divided by the numbers $\mathrm{I}, 2$, and 3 , the lengths of these sectional coils and their number of turns are as follows, correction being made for temperature and the calibration error of the bar:

\begin{tabular}{r|c|c}
\hline Coils & Number of turns & Length at $20^{\circ} \mathrm{C}$. \\
\hline 1 & 221 & $15.3347 \mathrm{~cm}$ \\
2 & 251 & 17.3565 \\
3 & 189 & 13.1945 \\
$1+2+3$ & 661 & 45.8857 \\
$1+2$ & 472 & 32.6912 \\
$2+3$ & 440 & 30.5510 \\
\hline
\end{tabular}

The coefficients used to reduce these values were for the brass meter bar:

$$
a=\mathrm{IO}^{-8}(\mathrm{I} 8 \mathrm{I} 4.2+0.66 t)
$$


and for the coil the coefficient of expansion of marble, as the coil in sinking from the high temperature at which it was wound would separate the turns, and they would then move with the marble and not as if they formed a copper sheet. The mean temperature of the bar was $23^{\circ}$. Io $\mathrm{C}$, and that of the marble was $22^{\circ} .62 \mathrm{C}$.

The coefficient for marble was used because the wires would decrease in diameter with decreasing temperature faster than the marble would pull them together, and the amount by which they would separate would be equal to the difference in contraction of a copper over a marble cylinder divided by the number of turns minus one.

\section{PART II.}

\section{THEORY OF THE CALCULATION OF STANDARDS OF MUTUAL AND SELF INDUCTANCE.}

Six methods will be given, some of which are applicable to the calculation of mutual and others to self-inductance. These methods assume different degrees of importance, depending upon the dimensions of the coil or coils. Some are applicable to short coils only and some to long coils only, while others apply to any coil. Some are approximate, although correct to a high degree of accuracy if applied to a coil of the right shape, while two are absolute formulæ.

The conditions for the use of the different methods will be given under the description of them.

\section{METHOD I.}

\section{SELF-INDUCTANCE BY SUMMATION OF A FINITE SERIES.}

In Maxwell's treatise ${ }^{1}$ will be found the following well-known expression for the mutual inductance between two coaxial parallel circles in terms of elliptic integrals of the first and second kinds to modulus $k$.

$$
\begin{aligned}
& M=4 \pi \sqrt{a A}\left\{\left(\frac{2}{k}-k\right) F-\frac{2}{k} E\right\} \\
& k^{2}=\frac{4 a A}{(a+A)^{2}+b^{2}}
\end{aligned}
$$


where $a$ and $A$ are the radii of the circles, respectively; and $b$ the distance between their planes.

Formula (I) above can be transformed into the following:

$$
M=8 \pi \sqrt{a A} \frac{\mathrm{I}}{\sqrt{k_{1}}}\left\{F\left(k_{1}\right)-E\left(k_{1}\right)\right\}
$$

where $k_{1}=\frac{r_{1}-r_{2}}{r_{1}+r_{2}}$ and $r_{1}$ and $r_{2}$ are the greatest and least distances from one circle to the other, respectively, as in Fig. 7 .

Taking an angle $\gamma$, such that its cosine is $\frac{r_{2}}{r_{1}}$ Lord Rayleigh has calculated the values ${ }^{1}$ of $\frac{M}{4 \pi \sqrt{a A}}$ for intervals of six minutes of angle for $\gamma$ between $60^{\circ}$ and $90^{\circ}$.

If the radii of the two circles are equal this angle is $\phi$, the angle between the maximum and minimum lines in Fig. 7.

When $\phi=90^{\circ}$, the two circles are coincident and the self-inductance of a circular filament (of zero cross-section) is infinite. When $\phi=60^{\circ}$, the circles are at a distance apart equal to $\frac{2 \sqrt{3}}{3}$ times their common radius. This is about I.I 5 times that radius. As for other reasons the length of the standard was nearly $\sqrt{3}$ times the radius, it follows that not every element of the present coil can be calculated by the table of Lord

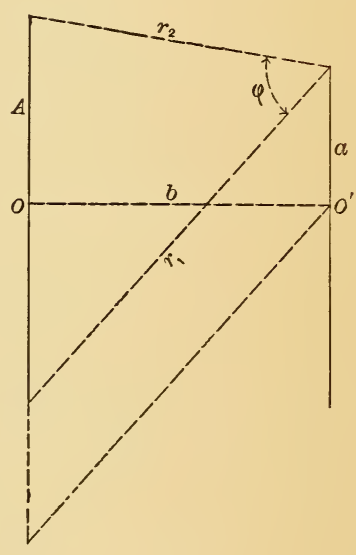

Fig. 7. Rayleigh. A plot, Fig. 8, has been made of these values of $\frac{M}{4 \pi \sqrt{a A}}$, which shows graphically how the mutual inductance of the two circles varies as we separate them from each other.

Professor Nagaoka has shown ${ }^{2}$ that the mutual inductance between two parallel coaxial circles can also be expressed in terms of $\theta$ functions, and has given the necessary formulæ. It is easy, on

${ }^{2}$ Phil. Mag., p. I9, July, I903. 
account of the extreme rapidity of the convergence of the series he deduces, to calculate $M$ by means of the $q$-series derived from the formulæ in terms of the $\theta$-functions.

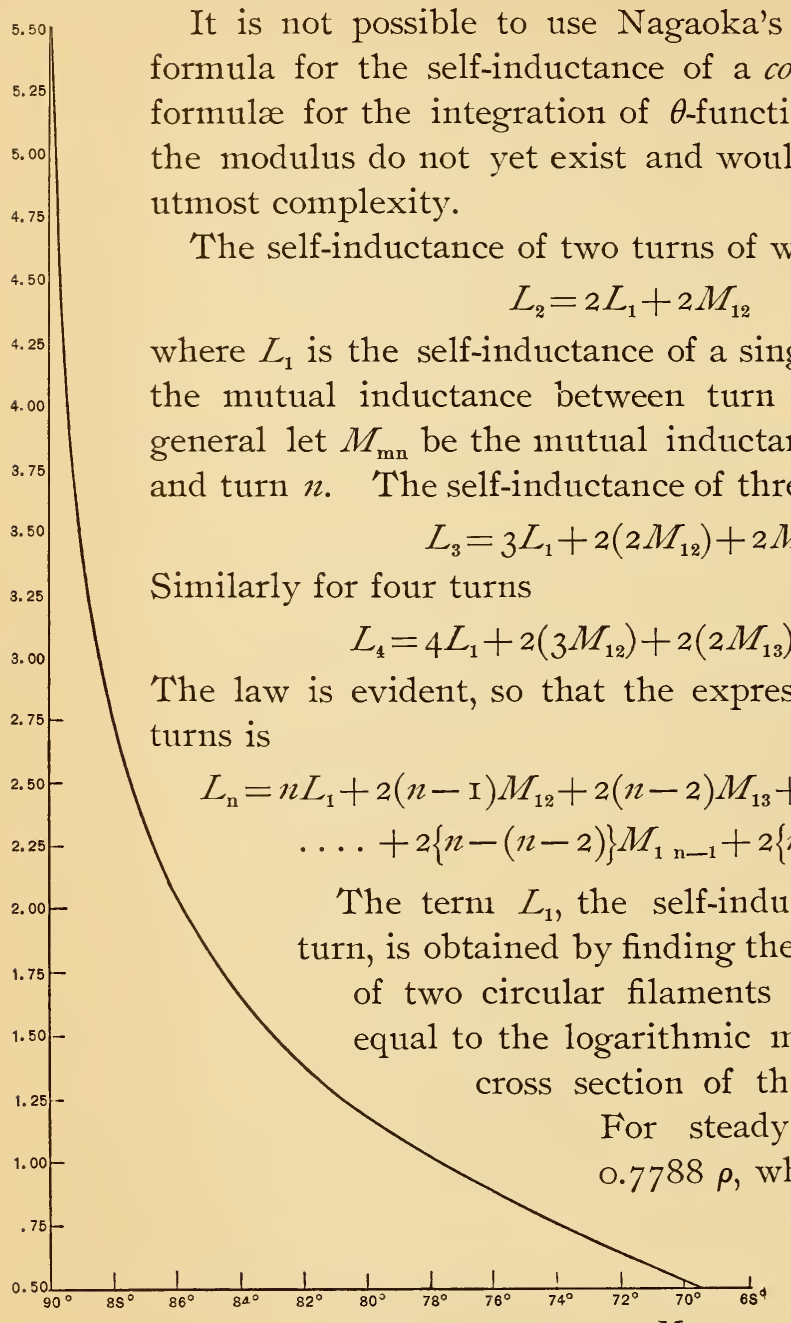

Fig. 8.-Curve. Ordinates Represent Values of $\frac{M}{4 \pi \sqrt{a A}}$.

Abscissas Represent Values of the Modulus $\gamma$. 
It is thus seen that this method gives a means of computing the difference in self-inductance of a coil due to a change of frequency of the currents in it.

This method is proposed for the computation of coils with a small number of turns, say, 20 or 30 . Such a computation will require as many interpolations from the table of Lord Rayleigh, as there are turns in the coil. A small portion of the table will cover the corresponding angles $\phi$ for such a coil. Form the first and second differences and use the interpolation formula

$$
A(x)=A+x\left(\delta A-\frac{1-x}{2}\left(\delta^{2} A-\frac{2-x}{3}\left(\delta^{3} A-\frac{3-x}{4}\left(\delta^{4} A \text { etc. }\right)\right.\right.\right.
$$

$A(x)$ is the required interpolated value, and $\delta A, \delta^{2} A, \delta^{3} A$ etc. are the first, second, and third differences, respectively, and $x$ is the difference between the parameter for which the function $A$ is desired, and the nearest one preceding it in the table.

This interpolation formula is to be found in Légendre, Traité des Fonctions Elliptiques. Having obtained these values, it is easy by means of a multiplying and adding machine to obtain the value of the self-inductance sought.

\section{METHOD II.}

\section{SELF-INDUCTANCE BY CONVERGING INFINITE SERIES.}

In Maxwell ${ }^{1}$ will be found the following well-known series for the mutual inductance between two circles, whose radii are $a$ and $a+y$, and whose distance apart is $x$.

$$
\begin{aligned}
& M=4 \pi a \log \frac{8 a}{r}\left(\mathrm{I}+\frac{1}{2} \frac{y}{a}+\frac{y^{2}+3 x^{2}}{\mathrm{I} 6 a^{2}}-\frac{y^{3}+3 x^{2} y}{32 a^{3}}+\ldots\right) \\
& +4 \pi a\left(-2-\frac{1}{2} \frac{y}{a}+\frac{3 v^{2}-x^{2}}{\mathrm{I} 6 a^{2}}-\frac{y^{3}-6 x^{2} y}{48 a^{3}}+\ldots\right)
\end{aligned}
$$

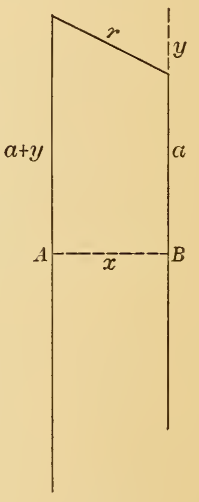

Fig. 9.

$r$ is the least distance from one wire to the other, as shown in Fig. 9.

If the two circles be assumed to have the same radius $a$, the formula (5) becomes, noticing that $y=0$ and $r=x$ in this case,

$$
M=4 \pi a \log \frac{8 a}{x}\left(1+\frac{3}{16} \frac{x^{2}}{a^{2}}+\ldots\right)+4 \pi a\left(-2-\frac{1}{1} \frac{x^{2}}{a^{2}}+\ldots\right)
$$

${ }^{1}$ Elec. and Mag., Vol. II, page 345. Third edition. 
By integrating equation (5) over the cross section of a circular coil with rectangular cross section, Weinstein ${ }^{1}$ has shown that the selfinductance of such a coil may be given by the following formula:

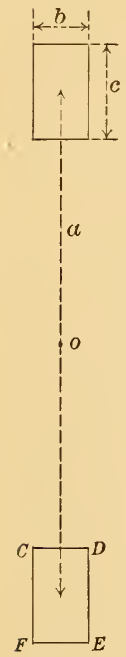

$a$ is the mean radius of coil,

$b$ is the axial breadth,

$c$ is the radial depth.

$$
L=4 \pi n^{2}(a \lambda+\mu)
$$

where, writing $x$ for $b / c$,

$$
\begin{gathered}
\lambda=\log \frac{8 a}{c}+\frac{\mathrm{I}}{\mathrm{I} 2}-\frac{\pi x}{3}-\frac{\mathrm{I}}{2} \log \left(\mathrm{I}+x^{2}\right)+\frac{\mathrm{I}}{\mathrm{I} 2 x^{2}} \log \left(\mathrm{I}+x^{2}\right) \\
+\frac{\mathrm{I}}{\mathrm{I} 2} x^{2} \log \left(\mathrm{I}+\frac{\mathrm{I}}{x^{2}}\right)+\frac{2}{3}\left(x-\frac{\mathrm{I}}{x}\right) \tan ^{-1} x,
\end{gathered}
$$

$$
\mu=\frac{c^{2}}{96 a}\left[\left(\log \frac{8 a}{c}-\frac{\mathrm{I}}{2} \log \left(\mathrm{I}+x^{2}\right)\right)\left(\mathrm{I}+3 x^{2}\right)+3 \cdot 45 x^{2}+\frac{22 \mathrm{I}}{6 \mathrm{O}}\right.
$$

Fig. 10. $\left.-\mathrm{I} .6 \pi x^{3}+3.2 x^{3} \tan ^{-1} x-\frac{\mathrm{I}}{\mathrm{IO}} \frac{\mathrm{I}}{x^{2}} \log \left(\mathrm{I}+x^{2}\right)+\frac{\mathrm{I}}{2} x^{4} \log \left(\mathrm{I}+\frac{\mathrm{I}}{x^{2}}\right)\right](7)$

This formula reduces to the special cases independently worked out by Mr. Niven and Lord Rayleigh, given below. The formula is here reprinted because, as printed in the second edition of Maxwell, it is inaccurate, although correct in the third edition.

Stefan $^{2}$ has very materially reduced the labor of computation by this formula by presenting it in the following form: In Table I $x=\frac{c}{b}$

$$
L=4 \pi a n^{2}\left[\left(I+\frac{3 b^{2}+c^{2}}{96 a^{2}}\right) \log \frac{8 a}{\sqrt{b^{2}+c^{2}}}-y_{1}+\frac{b^{2}}{16 a^{2}} y_{2}\right]
$$

Stefan ${ }^{3}$ gives the following formula, without proof, for the correction to be applied to the self-inductance of a coil to take into account the insulation of the wire:

$$
\Delta L=4 \pi a n\left\{\log \frac{D}{d}+\text { o.I } 5494\right\}
$$

${ }^{1}$ Wied. Annalen, 21, pp. 329-350, I884; Maxwell, Vol. II, Appendix, p. 350.

${ }^{2}$ Wied. Annalen, 22, pp. I07-II7, I884.

${ }^{3}$ Wied. Annalen, 22, p. I16; 1884. 
This correction is to be added to the self-inductance computed by any of the formulæ just given, where there are a number of layers of wire in the cross section of the coil.

$$
\begin{aligned}
n & =\text { total number of turns. } \\
a & =\text { mean radius of the coil. } \\
D & =\text { diameter of covered wire. } \\
d & =\text { diameter of bare wire. }
\end{aligned}
$$

Maxwell, Volume II, page 329, gives the number O.II835 instead of 0.15494 .

TABLE I.

Showing Values of the Constants $y_{1}$ and $y_{2}$ of Equation (8).

\begin{tabular}{c|c|c|c|c|c}
\hline $\mathrm{x}$ & \multicolumn{1}{c|}{$\mathrm{y}_{1}$} & \multicolumn{1}{c|}{$\mathrm{y}_{2}$} & \multicolumn{1}{c|}{$\mathrm{x}$} & \multicolumn{1}{c}{$\mathrm{y}_{1}$} & \multicolumn{1}{c}{$\mathrm{y}_{2}$} \\
\cline { 2 - 3 } \cline { 5 - 6 } 0.00 & 0.50000 & 0.1250 & 0.50 & 0.79600 & 0.3066 \\
.05 & .54899 & .1269 & .55 & .80815 & .3437 \\
.10 & .59243 & .1325 & .60 & .81823 & .3839 \\
.15 & .63102 & .1418 & .65 & .82648 & .4274 \\
.20 & .66520 & .1548 & .70 & .83311 & .4739 \\
.25 & .69532 & .1714 & .75 & .83831 & .5234 \\
.30 & .72172 & .1916 & .80 & .84225 & .5760 \\
.35 & .74469 & .2152 & .85 & .84509 & .6317 \\
.40 & .76454 & .2423 & .90 & .84697 & .6902 \\
.45 & .78155 & .2728 & .95 & .84801 & .7518 \\
.50 & .79600 & .3066 & 1.00 & .84834 & .8162 \\
\hline
\end{tabular}

The following formulæ, equations (9) and (Io), independently worked out by Lord Rayleigh ${ }^{1}$ and Mr. Niven, may be obtained from equation (7) by giving the proper values to $x$. The formulæ so deduced are very good approximations when the cross section of the coil is small compared with the area inclosed by a single turn.

(a) For a coil whose axial dimension is zero (that is, a flat spiral), $b=0$, and the self-inductance is given by the formula

$$
L=4 \pi n^{2} a\left[\log \frac{8 a}{c}-\frac{\mathrm{I}}{2}+\frac{c^{2}}{96 a^{2}}\left(\log \frac{8 a}{c}+\frac{43}{\mathrm{I} 2}\right)\right]
$$


(b) For a coil whose radial dimension is zero (that is, a cylindrical coil of a single layer), $c=0$, and the self-inductance is given by the formula

$$
L=4 \pi n^{2} a\left[\log \frac{8 a}{b}-\frac{\mathrm{I}}{2}+\frac{b^{2}}{32 a^{2}}\left(\log \frac{8 a}{b}+\frac{\mathrm{I}}{4}\right)\right]
$$

Formula (Io) was derived independently by the writer, not knowing in what manner it was obtained by the above-mentioned mathematicians.

(c) For a coil of circular cross section, the self-inductance is given by the following formula obtained by integration of equation (5) over a circular area,

$$
L=4 \pi n^{2} a\left[\log \frac{8 a}{\rho}-\frac{7}{4}+\frac{\rho^{2}}{8 a^{2}}\left(\log \frac{8 a}{\rho}+\frac{\mathrm{x}}{3}\right)\right]
$$

In these three formulæ

$n$ is the total number of turns in the coil.

$a$ is the mean radius of coil.

$b$ is the axial dimension.

$c$ is the radial dimension.

$\rho$ is the radius of circular cross-section.

These formulæ are obtained by integrating the series of equation (5) over the cross-section of the coil. In particular, formula (ro) is obtained by the integration of equation (6).

In order to compute a more accurate expression for the selfinductance of a cylindrical coil of a single layer, whose axial dimension $b$ is large compared with the radius $a$ of the coil it was necessary to compute more terms of the series (6).

By expanding the terms of

$$
\frac{M}{4 \pi \alpha}=\left\{\left(\frac{2}{\kappa}-\kappa\right) F(\kappa)-\frac{2}{\kappa} E(\kappa)\right\}
$$

in infinite series and combining them, three extra terms were obtained to the series of Maxwell, equation (6), for the case in which $y$ is put equal to zero (the condition for equal radii). 
To do this it was necessary to employ the following expansions. ${ }^{1}$

$$
\begin{aligned}
& \kappa^{2}=\frac{4 a^{2}}{4 a^{2}+x^{2}}=\frac{\mathrm{I}}{\mathrm{I}+c^{2}}, \text { if } \frac{x^{2}}{4 a^{2}}=c^{2} \\
& \kappa^{2}+\kappa^{\prime 2}=\mathrm{I} \quad \kappa^{\prime} \text { is the complementary modulus. } \\
& F(\kappa)=\log \frac{4}{\kappa^{\prime}}+\frac{\mathrm{I}^{2}}{2^{2}} \kappa^{\prime 2}\left(\log \frac{4}{\kappa^{\prime}}-\frac{2}{\mathrm{I} \cdot 2}\right) \\
& +\frac{\mathrm{I}^{2}}{2^{2}} \frac{3^{2}}{4^{2}} \kappa^{\prime 4}\left(\log \frac{4}{\kappa^{\prime}}-\frac{2}{\mathrm{I} \cdot 2}-\frac{2}{3 \cdot 4}\right) \\
& +\frac{\mathrm{I}^{2}}{2^{2}} \frac{3^{2}}{4^{2}} \frac{5^{2}}{6^{2}} \kappa^{\prime 6}\left(\log \frac{4}{\kappa^{\prime}}-\frac{2}{\mathrm{I} \cdot 2}-\frac{2}{3 \cdot 4}-\frac{2}{5 \cdot 6}\right) \\
& +\frac{\mathrm{I}^{2}}{2^{2}} \frac{3^{2}}{4^{2}} \frac{5^{2}}{6^{2}} \frac{7^{2}}{8^{2}} \kappa^{\prime 8}\left(\log \frac{4}{\kappa^{\prime}}-\frac{2}{\mathrm{I} \cdot 2}-\frac{2}{3 \cdot 4}-\frac{2}{5 \cdot 6}-\frac{2}{7 \cdot 8}\right) \\
& +\ldots \\
& E(\kappa)=\quad \mathrm{I}+\frac{\mathrm{I}}{2} \kappa^{\prime 2}\left(\log \frac{4}{\kappa^{\prime}}-\frac{\mathrm{I}}{\mathrm{I} \cdot 2}\right) \\
& +\frac{\mathrm{I}^{2}}{2^{2}} \frac{3}{4} \kappa^{\prime 4}\left(\log \frac{4}{\kappa^{\prime}}-\frac{2}{\mathrm{I} \cdot 2}-\frac{\mathrm{I}}{3 \cdot 4}\right) \\
& +\frac{\mathrm{I}^{2}}{2^{2}} \cdot \frac{3^{2}}{4^{2}} \frac{5}{6} \kappa^{\prime 6}\left(\log \frac{4}{\kappa^{\prime}}-\frac{2}{\mathrm{I} \cdot 2}-\frac{2}{3 \cdot 4}-\frac{\mathrm{I}}{5 \cdot 6}\right) \\
& +\frac{\mathrm{I}^{2}}{2^{2}} \frac{3^{2}}{4^{2}} \frac{5^{2}}{6^{2}} \frac{7}{8} \kappa^{\prime 8}\left(\log \frac{4}{\kappa^{\prime}}-\frac{2}{\mathrm{I} \cdot 2}-\frac{2}{3 \cdot 4}-\frac{2}{5 \cdot 6}-\frac{\mathrm{I}}{7.8}\right) \\
& +\ldots
\end{aligned}
$$

Putting $c=\frac{x}{2 a}$ the formula derived is

$$
\begin{aligned}
& \frac{M}{4 \pi a}=\log \frac{4}{c}\left\{\mathrm{I}+\frac{3}{4} c^{2}-\frac{\mathrm{I} 5}{64} c^{4}+\frac{35}{256} c^{6}-\frac{\mathrm{I} 575}{(\mathrm{I} 28)^{2}} c^{8}+\ldots\right\} \\
& +\left\{-2-\frac{\mathrm{I}}{4} c^{2}+\frac{3 \mathrm{I}}{\mathrm{I} 28} c^{4}-\frac{247}{\mathrm{I} 536} c^{6}+\frac{\mathrm{I} 63,695}{(\mathrm{I} 28)^{2} \times 84} c^{8}-\ldots .\right\}
\end{aligned}
$$

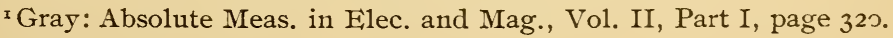
24353-No. I-06-8 
The last three terms in each of the parentheses are the new terms, and form a continuation of Maxwell's formula, equation (6), for the case $y=0$. Hence, this formula gives the mutual inductance between two circles of the same radius, when placed at a distance apart equal to $x$.
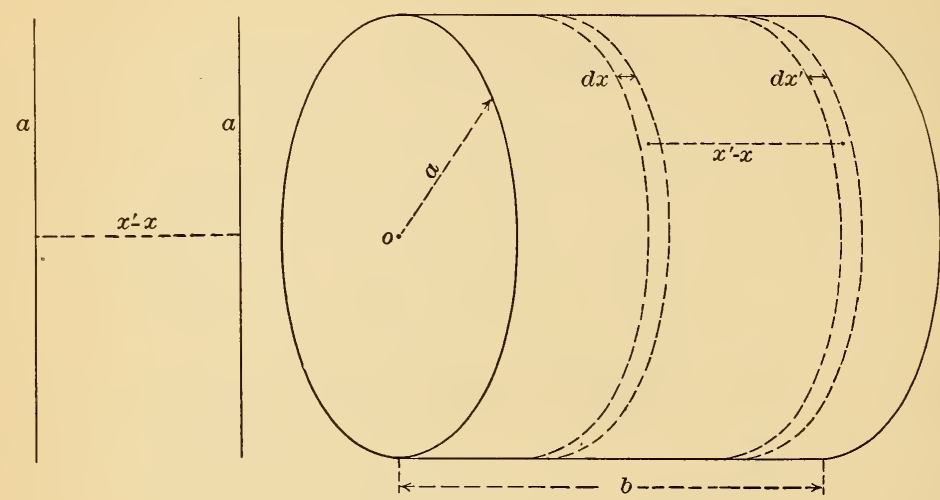

Fig. 11.

Consider a current sheet, the current in it being unity and the length of the circular cylindrical sheet being $b$.

Then in a length $d x$ there will be a current $\frac{d x}{b}$ and in another element $d x^{\prime}$ a current of strength $\frac{d x^{\prime}}{b}$. The mutual inductance between these two circular elements is then

$$
d M=M_{x^{\prime}, x} \frac{d x}{b} \cdot \frac{d x^{\prime}}{b}
$$

where $M_{x^{\prime}, x}$ is the mutual inductance between two circular filaments at points whose coordinates are $x^{\prime}$ and $x$ and hence whose distance apart is $\left(x^{\prime}-x\right)$. The total self inductance of the current sheet is

$$
\mathrm{L}=\int_{-\frac{b}{2}}^{+\frac{b}{2}} \int_{-\frac{b}{2}}^{+\frac{b}{2}} M_{x^{\prime}, x} \frac{d x}{b} \cdot \frac{d x^{\prime}}{b}
$$




$$
=\frac{I}{b^{2}} \int_{-\frac{b}{2}}^{+\frac{b}{2}} d x^{\prime} \int_{-\frac{b}{2}}^{+\frac{b}{2}} M_{x^{\prime}, x} d x
$$

Using the following formulæ of integration, which may readily be deduced by integration by parts, we obtain formula (I3).

$$
\begin{gathered}
\int_{-\frac{b}{2}}^{+\frac{b}{2}} d x^{\prime} \int_{-\frac{b}{2}}^{+\frac{b}{2}}\left(x^{\prime}-x\right)^{n} \\
\log \left(x^{\prime}-x\right) d x=\frac{2 b^{n+2}}{(n+\mathrm{I})(n+2)} \log b \\
-\frac{2(2 n+3)}{(n+\mathrm{I})^{2}(n+2)^{2}} b^{n+2}
\end{gathered}
$$

where $n$ is integral, even and positive, and

$$
\begin{aligned}
& \int_{-\frac{b}{2}}^{+\frac{b}{2}} d x^{\prime} \int_{-\frac{b}{2}}^{+\frac{b}{2}}\left(x^{\prime}-x\right)^{n} d x=\frac{2}{(n+\mathrm{I})(n+2)} b^{n+2} \text { if } n \text { is even, } \\
& =0 \quad \text { if } n \text { is odd. } \\
& L=4 \pi a n^{2} \begin{cases}\left(\log \frac{8 a}{b}-\frac{\mathrm{I}}{2}\right)+\frac{b^{2}}{32 a^{2}}\left(\log \frac{8 a}{b}+\frac{\mathrm{I}}{4}\right) & A \\
-\frac{\mathrm{I}}{\mathrm{IO} 24} \frac{b^{4}}{a^{4}}\left(\log \frac{8 a}{b}-\frac{2}{3}\right) & B \\
+\frac{\mathrm{IO}}{\mathrm{I} 3 \mathrm{IO} 22} \frac{b^{6}}{a^{6}}\left(\log \frac{8 a}{b}-\frac{\mathrm{IO9}}{\mathrm{I} 20}\right) & C \\
-\frac{35}{4 \mathrm{I} 94304} \frac{b^{8}}{a^{8}}\left(\log \frac{8 a}{b}-\frac{43 \mathrm{I}}{420}\right)+\ldots & D\end{cases}
\end{aligned}
$$

The last three terms, $B, C, D$, are derived from the new terms of the extended equation of Maxwell. The terms marked $A$ are the well known ones for the special case, worked out by Lord Rayleigh and Mr. Niven.

This equation is comparatively easy to work with. It applies the better the shorter the coil. For a long coil, i. e. one as long as 44 
$\mathrm{cm}$ with a diameter of $54 \mathrm{~cm}$, it gives results about three or four parts in roo,ooo too small.

For such a coil the rapidity of convergence may be seen by the following set of values

$$
L=4 \pi a n^{2}\left\{1.091865+.152585-.00635^{2}+.000972-.000168\right\}
$$

For short coils the convergence is very rapid. The terms for a coil of length $2 \mathrm{I} \mathrm{cm}$, dianeter $54 \mathrm{~cm}$, are as follows:

$$
L=4 \pi a n^{2}\left\{\mathrm{I} .849647+.062003-.00055^{8}+.000022-.0000013\right\}
$$

The formula is thus seen to be practically exact up to eignt places of significant figures. This formula the writer considers the best for the calculation of the self inductance of cylindrical current sheets, as it does not require any special tables, and having once obtained the logarithms of the several numerical factors it is a matter of about forty minutes to compute the value of a coil with seven place tables correct to six places of significant figures.

For very long coils, this formula gives results a trifle too small and the computation of an extra term is desirable. It is, however, amply sufficient for the present purpose.

\section{METHOD III.}

SELF-INDUCTANCE IN TERMS OF ELLIPTIC INTEGRALS. EXACT FORMULA.

It is proposed to find the mutual inductance between two coaxial helices, using the Neumann formula

$$
M=\iint \frac{\cos \epsilon d s d s^{\prime}}{r}
$$

where $d s$ and $d s^{\prime}$ denote elements of arc of the respective circuits, $\epsilon$ the angle between these elements, and $r$ their distance apart. The integral is to be taken over both circuits.

Let the equations of the two helices be respectively:

$$
\begin{array}{ll}
y=a \cos \theta & y^{\prime}=A \cos \theta^{\prime} \\
z=a \sin \theta & z^{\prime}=A \sin \theta^{\prime} \\
x=p \theta & x^{\prime}=p^{\prime} \theta^{\prime}
\end{array}
$$


where $a$ and $A$ are the radii of the two helices, $p$ and $p^{\prime}$ their respective pitches, that is the amount advanced per radian of revolution, the amount advanced in one complete turn being $2 \pi p$. Neumann's formula, which in rectangular coordinates is

$$
M=\iint \frac{d x d x^{\prime}+d y d y^{\prime}+d z d z^{\prime}}{\sqrt{\left(x-x^{\prime}\right)^{2}+\left(y-y^{\prime}\right)^{2}+\left(z-z^{\prime}\right)^{2}}}
$$

becomes on substituting the required values

$$
M=\int_{\theta_{1}^{\prime}}^{\theta_{2^{\prime}}} \int_{\theta_{1}}^{\theta_{2}} \frac{\left\{p p^{\prime}+A a \cos \left(\theta-\theta^{\prime}\right)\right\} d \theta d \theta^{\prime}}{\left(p \theta-p^{\prime} \theta^{\prime}\right)^{2}+A^{2}+a^{2}-2 A \alpha \cos \left(\theta-\overline{\left.\theta^{\prime}\right)}\right.}
$$

This expression is unintegrable in terms of any known functions and therefore the general problem proposed is not solvable. Let us put $p=p^{\prime}$, i.e., make the two helices have the same pitch, then

$$
M=\iint \frac{\left\{p^{2}+A a \cos \left(\theta-\theta^{\prime}\right)\right\} d \theta d \theta^{\prime}}{\sqrt{p^{2}\left(\theta-\theta^{\prime}\right)^{2}+A^{2}+a^{2}-2 A a \cos \left(\theta-\theta^{\prime}\right)}}
$$

Change the variable, putting

We now have

$$
\begin{aligned}
\theta-\theta^{\prime} & =\phi \\
\theta^{\prime} & =\phi^{\prime}
\end{aligned}
$$

$$
M=\int_{\theta_{x^{\prime}}}^{\theta_{z^{\prime}}} \int_{0}^{\theta} \frac{\left(p^{2}+A a \cos \phi\right) d \phi d \phi^{\prime}}{\sqrt{p^{2} \phi^{2}+a^{2}+A^{2}-2 a A \cos \phi}}
$$

We can integrate this expression with respect to $\phi^{\prime}$ giving, if we make the number of turns an integral one, $n$ (say),

$$
M=2 \pi n \int_{0}^{2 n \pi} \frac{\left(p^{2}+A a \cos \phi\right) d \phi}{\sqrt{p^{2} \phi^{2}+A^{2}+a^{2}-2 A a \cos \phi}}
$$

This integral is still unmanageable.

Putting $p^{\prime}=0$, we obtain the mutual inductance between a circle and a coaxial helix; equation (I 5 ) then becomes,

$$
M=\int_{0}^{2 \pi} \int_{0}^{\theta_{1}} \frac{A a \cos \left(\theta-\theta^{\prime}\right) d \theta d \theta^{\prime}}{\sqrt{A^{2}+a^{2}-2 A a \cos \left(\theta-\theta^{\prime}\right)+p^{2} \theta^{2}}}
$$


This equation has been integrated by J. Viriamu Jones.

Take as new variable $\phi=\theta-\theta^{\prime}$ and put $a^{2}=A^{2}+a^{2}-2 A a \cos \phi$, we have

$$
M=\int_{-\theta}^{-\theta+2 \pi} \int_{0}^{\theta_{1}} \frac{A \alpha \cos \phi \cdot d \theta \cdot d \phi}{\sqrt{p^{2} \theta^{2}+a^{2}}}
$$

But we can find for every value of $\theta$ (that is, for every element of the helix) an element on the circle corresponding to a constant value of $\phi$. Hence, if we integrate first with respect to $\theta$ keeping $\phi$ constant, and then with respect to $\phi$ from o to $2 \pi$ we shall obtain the required integral. Thus,

$$
\begin{aligned}
M & =\int_{0}^{2 \pi} d \phi \int_{0}^{\theta_{1}} \frac{A a \cos \phi d \theta}{\sqrt{p^{2} \theta^{2}+a^{2}}} \\
& =\int_{0}^{2 \pi} d \phi \frac{A a \cos \phi}{p} \log \left\{\frac{p \theta_{1}}{a}+\sqrt{\mathrm{I}+\frac{p^{2} \theta_{1}^{2}}{a^{2}}}\right\}
\end{aligned}
$$

This expression is then the mutual inductance between a helix and a coaxial circle, the circle being in the plane of one end of the helix.

Prof. J. Viriamu Jones ${ }^{1}$ has found that this integral can be reduced to the expression

$$
M_{\theta_{\mathrm{I}}}=\theta_{1}(\mathrm{~A}+a) c k\left\{\frac{F-E}{k^{2}}+\frac{c^{\prime 2}}{c^{2}}(F-\Pi)\right\}
$$

$F, E$, and $\Pi$ are the complete elliptic integrals of the first, second, and third kinds, respectively, and

$$
\begin{aligned}
c^{2} & =\frac{4 A a}{(A+a)^{2}}, k^{2}=\frac{4 A a}{(A+a)^{2}+b^{2}}, \\
b & =\text { axial length of helix }, \\
-c^{2} & =-\mathrm{I}+k^{\prime 2} \sin ^{2} \beta, \text { and } \sin \beta=\frac{c^{\prime}}{k^{\prime}} .
\end{aligned}
$$

To find the mutual inductance between a helix and a current sheet, both circular and cylindrical, we may proceed in the follow-

${ }^{1}$ Phil. Trans. Roy. Soc., vol. 182 (I89I), A; Proc. Roy. Soc., vol. 63, page I92; Phil. Mag., Jan., I8S9. 
ing manner. Integrate the expression found for the mutual inductance between a circle and a helix, thus making the circle develop the cylindrical current sheet. If we call $x$ the variable along the axis of the current sheet, we easily see that the mutual inductance between a circle and a coaxial cylindrical circular current sheet is given by

$$
\begin{aligned}
M=\int_{x_{\mathrm{x}}}^{x_{2}} d x \int_{0}^{2 \pi} d \theta \int_{0}^{2 \pi} d \theta^{\prime} \frac{A a \cos \left(\theta-\theta^{\prime}\right)}{\sqrt{A^{2}+a^{2}-2 A a \cos \left(\theta-\theta^{\prime}\right)+x^{2}}} \\
=2 \pi \int_{0}^{2 \pi} d \phi \int_{x_{\mathrm{x}}}^{x_{2}} \frac{A a \cos \phi d x}{\sqrt{a^{2}+x^{2}}} \\
=2 \pi A a\left[\int_{0}^{2 \pi} \cos \phi \log \left(x_{2}+\sqrt{a^{2}+x_{2}^{2}}\right) d \phi\right. \\
\left.-\int_{0}^{2 \pi} \cos \phi \log \left(x_{1}+\sqrt{a^{2}+x_{1}^{2}}\right) d \phi\right]
\end{aligned}
$$

If the circle is in the plane of the end of the current sheet $x_{1}=0$ and the second integral of the last expression reduces to

$$
\int_{0}^{2 \pi} \cos \phi \log a d \phi
$$

which when combined with the first integral gives

$$
M=2 \pi A a \int_{0}^{2 \pi} \cos \phi \log \left(\frac{x_{2}}{a}+\sqrt{I+\frac{x_{2}^{2}}{a^{2}}}\right) d \phi
$$

Comparing this expression with equation (I6) we immediately see, since $p \theta$ is the axial length of the helix, that the mutual inductance between a circle and a coaxial helix is identically the same as that between a circle and a coaxial current sheet of same axial length as the helix and occupying the same position. This result was obtained by Professor Jones, and appears to the writer to be a remarkable one. It leads immediately to the conclusion that the mutual inductance 
between two coaxial current sheets is the same as that between a current sheet and a coaxial helix of same axial length and radius, and occupying the same position.

The writer has found an expression for this mutual inductance in terms of elliptic integrals of all three kinds.

Integrate expression (I8) from $x=x_{1}$ to $x=x_{2}$

$$
\begin{aligned}
& M=\int_{x_{1}}^{x_{2}} d x \int_{0}^{2 \pi} 2 \pi A a \cos \phi\left[\log \left(\frac{x_{2}{ }^{\prime}-x}{a}+\sqrt{\mathrm{I}+\frac{\left(x_{2}{ }^{\prime}-x\right)^{2}}{a^{2}}}\right)\right. \\
& -\log \left(\frac{x_{1}{ }^{\prime}-x}{a}+\sqrt{\left.\mathrm{I}+\frac{\left(x_{1}{ }^{\prime}-x\right)^{2}}{a^{2}}\right)}\right] d \phi \\
& =2 \pi A a \int_{0}^{2 \pi} \cos \phi \cdot d \phi\left[f\left(x_{2}{ }^{\prime}-x_{1}\right)-f\left(x_{2}{ }^{\prime}-x_{2}\right)+f\left(x_{1}{ }^{\prime}-x_{2}\right)-f\left(x_{1}{ }^{\prime}-x_{1}\right)\right] \\
& \text { where } \\
& f(z) \equiv z \log \left(\frac{z}{a}+\sqrt{\mathrm{I}+\frac{z^{2}}{a^{2}}}\right)-\sqrt{a^{2}+z^{2}} \\
& f(z)=\lambda(-z)
\end{aligned}
$$

If the axial length of the two current sheets be denoted by $2 m$ and $2 l$ respectively, and the distance apart of their mean planes by $x_{0}$, the expression becomes

$$
\begin{aligned}
& M=2 \pi A a \int_{0}^{2 \pi} \cos \phi \cdot d \phi\left[f\left(x_{0}+l+m\right)-f\left(x_{0}+l-m\right)+f\left(x_{0}-l-m\right)\right. \\
& \left.-f\left(x_{0}-l+m\right)\right]
\end{aligned}
$$

Equation (20a), which expresses the mutual inductance between a current sheet of length $2 m$ and radius $A$ and one of length $2 l$ and radius $\alpha$, may be integrated in a manner similar to the simpler one actually reduced.

The problem of the mutual inductance of two coaxial cylindrical circular current sheets may then be considered to be completely solved. 
If the two current sheets be made coincident in position and of the same axial length, i. e., letting $x_{0}=0$, and $2 l=2 m$, and using the relation (20) above, the equation reduces to

$$
M=4 \pi A a \int_{0}^{2 \pi} \cos \phi \cdot d \phi[f(2 m)-f(0)]
$$

As yet the two cylinders may differ in radii. Replacing $f(2 m)$ and $f(\mathrm{o})$ by their equivalents (see eq. (20)) the following equation is obtained, and it remains to reduce it to elliptic integrals of standard form.

$$
\begin{aligned}
\frac{M}{4 \pi A a}= & {\left[\int_{0}^{2 \pi} \cos \phi \cdot d \phi b \log \left(\frac{b}{a}+\sqrt{I+\frac{b^{2}}{a^{2}}}\right)\right.} \\
& -\int_{0}^{2 \pi} \cos \phi \cdot d \phi \sqrt{b^{2}+a^{2}} \\
& \left.+\int_{0}^{2 \pi} \cos \phi \cdot d \phi \sqrt{\mathrm{o+a^{2 }}}\right]
\end{aligned}
$$

where $b=$ axial length.

We may now proceed to determine the above three integrals in turn, designating them as $P, Q$, and $R$, respectively.

Integrating the first integral $(P)$ by parts, a new expression is obtained, of which the integrated portion vanishes at the limits, giving:

$$
P=b^{2} A a \int_{0}^{2 \pi} \frac{\sin ^{2} \phi d \phi}{a^{2} \sqrt{a^{2}+b^{2}}}
$$

Now make the following substitution

$$
\psi=\frac{\pi}{2}-\frac{\phi}{2} \text { or } \phi=\pi-2 \psi
$$

Then

$$
\begin{aligned}
\sin \phi=\sin (\pi-2 \psi) & =\sin 2 \psi=2 \sin \psi \cos \psi \\
\cos \phi=\cos (\pi-2 \psi) & =-\cos 2 \psi=2 \sin ^{2} \psi-\mathrm{I} \\
d \phi & =-2 d \psi
\end{aligned}
$$


The limits are now $-\frac{\pi}{2}$ and $\frac{\pi}{2}$ instead of $2 \pi$ and $\mathrm{o}$. If we call

$$
\begin{gathered}
z^{2}=(A+a)^{2}+b^{2} \\
k^{2}=\frac{4 A a}{(A+a)^{2}+b^{2}}=\frac{4 A a}{z^{2}} \\
c^{2}=\frac{4 A a}{(A+a)^{2}}=\mathrm{I}-c^{\prime 2}
\end{gathered}
$$

the integral (23) may be written

$$
P=\frac{16 b^{2} A a}{z(A+a)^{2}} \int_{0}^{\frac{\pi}{2}} \frac{\sin ^{2} \psi \cos ^{2} \psi d \psi}{\left(\mathrm{I}-c^{2} \sin ^{2} \psi\right) \sqrt{\mathrm{I}-\kappa^{2} \sin ^{2} \psi}}
$$

The value of this integral has been found by Jones ${ }^{1}$ to be:

$$
P=\frac{b^{2}(A+a)}{A a} c k\left\{\frac{F-E}{k^{2}}+\frac{c^{\prime 2}}{c^{2}}(F-\Pi)\right\}
$$

In Cayley's Treatise on Elliptic Functions, section I83, may be found the following relation:

$k^{\prime 2} \sin \beta \cos \beta(F-\Pi)=-\frac{\Pi}{2}-F(k) F\left(k^{\prime} \beta\right)+E(k) F\left(k^{\prime} \beta\right)+F(k) E\left(k^{\prime} \beta\right)$ where

$$
\sin \beta=\frac{\sqrt{\mathrm{I}-c^{2}}}{k^{\prime}}=\frac{c^{\prime}}{k^{\prime}}, k^{\prime 2}=\mathrm{I}-k^{2}
$$

and

$$
-c^{2}=-\mathrm{I}+k^{\prime 2} \sin ^{2} \beta
$$

by means of which the necessary integral $\Pi$ may be calculated.

To express the second part of the integral $Q=\int_{0}^{2 \pi} \cos \phi \sqrt{a^{2}+b^{2}} d \phi$

$$
\text { put } \psi=\frac{\pi}{2}-\frac{\phi}{2}
$$

then $\cos \psi=\sin \frac{\phi}{2}$

$$
\sin \psi=\cos \frac{\phi}{2}
$$

${ }^{1}$ Loc. cit. 


$$
\begin{aligned}
\cos \phi & =2 \cos ^{2} \frac{\phi}{2}-\mathrm{I} \\
\mathrm{I}+\cos \phi & =2 \cos ^{2} \frac{\phi}{2} \\
a^{2}+b^{2} & =A^{2}+a^{2}+2 a A+b^{2}-2 A a(\cos \phi+\mathrm{I}) \\
& =(A+a)^{2}+b^{2}-4 A a \cos ^{2} \frac{\phi}{2} \\
a^{2}+b^{2}= & z^{2}\left(\mathrm{I}-\frac{4 A a}{z^{2}} \sin ^{2} \psi\right)=z^{2}\left(\mathrm{I}-k^{2} \sin ^{2} \psi\right)
\end{aligned}
$$

where $k^{2}=\frac{4 A a}{z^{2}}$ and is always less than unity.

$$
Q=\int_{\frac{\pi}{2}}^{\frac{-\pi}{2}} z \sqrt{I-k^{2} \sin ^{2} \psi}\left(2 \sin ^{2} \psi-I\right)(-2 d \psi)
$$

This integral being an even function we may write

$$
\begin{aligned}
& Q=4 z \int_{0}^{\frac{\pi}{2}} \sqrt{I-k^{2} \sin ^{2} \psi}\left(2 \sin ^{2} \psi-I\right) d \psi \\
& =8 z \int_{0}^{\frac{\pi}{2}} \frac{\sin ^{2} \psi\left(I-k^{2} \sin ^{2} \psi\right)}{\sqrt{I-k^{2} \sin ^{2} \psi}} d \psi-4 z \int_{0}^{\frac{\pi}{2}} \sqrt{I-k^{2} \sin ^{2} \psi} d \psi \\
& =8 z \int_{0}^{\frac{\pi}{2}} \frac{\sin ^{2} \psi d \psi}{\Delta \psi}-8 z k^{2} \int_{0}^{\frac{\pi}{2}} \frac{\sin ^{4} \psi d \psi}{\Delta \psi}-4 z E(k) \\
& =Q_{1}-Q_{2}+Q_{3} \text {, say }
\end{aligned}
$$

where $\Delta \psi=\sqrt{I-k^{2} \sin ^{2} \psi}$

Now by Bierens de Haan's tables of definite integrals,

$$
Q_{1}=8 z \frac{I}{k^{2}}\{F(k)-E(k)\}
$$


and

$$
\left.Q_{2}=8 z k^{2} \frac{\mathrm{I}}{3 k^{4}} \mid\left(2+k^{2}\right) F(k)-2\left(\mathrm{I}+k^{2}\right) E(k)\right\}
$$

Both of these formulæ have been verified independently by direct reduction. ${ }^{1}$

The second part of the integral $Q=Q_{1}-Q_{2}-Q_{3}$ is therefore

$$
\begin{aligned}
Q= & \left.\frac{8 z}{3 k^{2}} \mid 3 F-3 E-\frac{3}{2} k^{2} E-\left(2+k^{2}\right) F+2\left(\mathrm{I}+k^{2}\right) E\right\} \\
& =\frac{4 z}{3 k^{2}}\left\{2\left(\mathrm{I}-k^{2}\right) F(k)+\left(k^{2}-2\right) E(k)\right\}
\end{aligned}
$$

$R$ is expressed in the same way that $Q$ is, excepting that $b$ is put equal to zero, which gives $z=A+\alpha$ and $k_{0}{ }^{2}=\frac{4 A a}{(A+a)^{2}}=c^{2}$. Inserting these values, we obtain

$$
R=\frac{2}{3} \frac{(A+a)}{A a}\left\{(A-a)^{2} F\left(k_{0}\right)-\left(A^{2}+a^{2}\right) E\left(k_{0}\right)\right\}
$$

The problem then by this method is completely solved, as we have

$$
\frac{M}{4 \pi A a}=P-Q+R
$$

It was at first thought that instead of putting $A=\alpha$ for the coefficient of mutual inductance of two coincident current sheets, which would give the self-inductance of a single such current sheet, it might be found more accurate to compute the mutual inductance of two such current sheets of radii $a+r^{2}$ and $a-r 2$, where $r$ is the logarithmic mean distance of the cross section of the wire, a circle, from itself. This is given ${ }^{2}$ by $r=0.7788 \rho$ where $\rho$ is the radius of the section of the wire. More accurately it is $r=\rho e^{-3 / 4}$.

By direct calculation it is found that this refinement is unnecessary, the result being the same to seven significant figures whether $a$ be put equal to $A$, or whether the above suggestion be followed.

${ }^{1}$ Jordan, Traité d'Analyse, II, 22.

${ }^{2}$ Maxwell, Elec. and Mag., Vol. II, page 324. Third edition. 
There is, however, a direct and important gain in simplicity by putting $a=A$.

In this case $c=\mathrm{r}$ and $c^{\prime}=\mathrm{O}$ in equation (24).

The equation for $P$ then simplifies into

$$
\begin{aligned}
& P=\frac{4 b^{2}}{z} \frac{F-E}{k^{2}} \\
& Q=\frac{4 z}{3 k^{2}}\left\{2\left(1-k^{2}\right) F-\left(2-k^{2}\right) E\right\}
\end{aligned}
$$

and

$$
\begin{aligned}
& R=-\frac{8}{3} a \\
& k^{2}=\frac{4 a^{2}}{4 a^{2}+b^{2}} \text { and } z=\sqrt{4 a^{2}+b^{2}}
\end{aligned}
$$

Hence

$$
L^{\prime}=4 \pi a^{2}\{P-Q+R\}
$$

This is the self-inductance on the assumption that the current per unit length of current sheet is unity. If there are $n_{1}$ turns of wire per unit of length in the coil, and unit current flows in each turn, the corresponding current in the current sheet would be $n_{1}$ units instead of one, and as this current enters to the second power the self-inductance of a cylindrical coil is

$$
L=4 \pi a^{2} n_{1}^{2}\{P-Q+R\}
$$

We may replace $n_{1}$ by $\frac{n}{b}$ and the equation becomes finally

$$
\begin{aligned}
L=4 \pi a^{2} \frac{n^{2}}{b^{2}} \mid \frac{4 b^{2}}{\sqrt{4 a^{2}+b^{2}}}\left(\frac{F-E}{k^{2}}\right) & -\frac{4 \sqrt{4 a^{2}+b^{2}}}{3 k^{2}}\left(2\left(1-k^{2}\right) F-\left(2-k^{2}\right) E\right) \\
& \left.-\frac{8}{3} a\right\}
\end{aligned}
$$

This formula involves finding the complete elliptic integrals of the first and second kinds only, a fairly easy matter, using Legendre's tables. 
Calling $2 a=d$ this equation may be reduced to the following, suggested by the formula of Method IV. Hence, for the case considered the above equation (3I) and the corresponding one of method VI are identical and equal to

$$
L=\frac{4}{3} \pi \frac{n^{2}}{b^{2}}\left\{p\left(d^{2}-b^{2}\right) E+p b^{2} F-d^{3}\right\}
$$

where

$$
\begin{aligned}
d & =\text { diameter of cylinder }=2 a \\
b & =\text { length of cylinder } \\
p^{2} & =d^{2}+b^{2} \\
k^{2} & =\frac{d^{2}}{d^{2}+b^{2}}=\frac{d^{2}}{p^{2}}
\end{aligned}
$$

$k$ is the modulus of the elliptic integrals $E$ and $F$.

By computing, however, with both formulæ (3I) and (32) a valuable check on the work is obtained. This was done by the writer before the equivalence of the two formulæ was discovered.

This equivalence also, of course, gives a check upon the theoretical accuracy of both the formulæ of this method and that of method IV.

\section{METHOD IV.}

MUTUAL AND SELF INDUCTANCE BY MEANS OF ELLIPTIC INTEGRALS, DUE TO KIRCHHOFF.

The following formula is an unpublished formula of Kirchhoff's for the mutual inductance between two coaxial cylindrical current sheets, symmetrically placed:

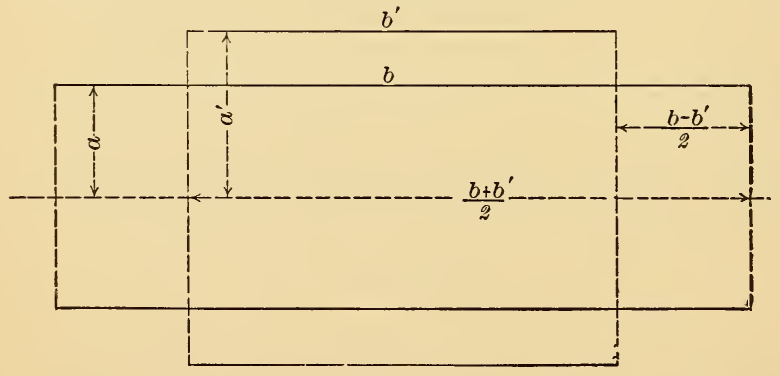

Fig. 12.

Let $a$ and $a^{\prime}$ be the radii of the internal and external solenoids, respectively. 
$b$ and $b^{\prime}$ the corresponding lengths.

$n$ and $n^{\prime}$ the total number of turns in each.

Then the mutual inductance between the two solenoids is given by the following expression:

$$
M=4 \pi^{2} \frac{n}{b} \frac{n^{\prime}}{b^{\prime}} a^{2} b^{\prime}+\left(V_{1}-V\right)
$$

where

$$
\begin{aligned}
V=4 & \frac{n}{b} \cdot \frac{n^{\prime}}{b^{\prime}} \pi\left\{\left(a^{\prime}-a\right) c^{2}[(F(q)-E(q)) F-F(q) E]\right. \\
& +\frac{\sqrt{c^{2}+\left(a^{\prime}+a\right)^{2}}}{3}\left[2\left(a^{\prime 2}+a^{2}\right)-c^{2}\right] E \\
& +\frac{c^{4}+2 c^{2}\left(a^{\prime 2}+a^{2}\right)-2\left(a^{\prime 2}-a^{2}\right)^{2}}{3 \sqrt{c^{2}+\left(a^{\prime}+a\right)^{2}}} F \\
& \left.+c a^{2} \pi\right\}
\end{aligned}
$$

and where

$$
c=\frac{b-b^{\prime}}{2} \text { in the expression for } V
$$

and

$$
c=\frac{b+b^{\prime}}{2}=c^{\prime} \text { in the expression for } V_{1}
$$

$F$ and $E$ are the complete elliptic integrals of the first and second kinds respectively, to modulus $k$, where

$$
k^{2}=\frac{4 a a^{\prime}}{c^{2}+\left(a^{\prime}+a\right)^{2}}
$$

$F(q)$ and $E(q)$ are the incomplete elliptic integrals of the first and second kinds, respectively, to modulus $k_{1}$ given by

$k_{1}^{2}=\frac{c^{2}+\left(a^{\prime}-a\right)^{2}}{c^{2}+\left(a^{\prime}+a\right)^{2}}$, their amplitude being given by the following equations : 


$$
\begin{gathered}
\sin \operatorname{am} q=\frac{c}{\sqrt{c^{2}+\left(a^{\prime}-a\right)^{2}}} ; \cos a m q=\frac{a^{\prime}-a}{\sqrt{c^{2}+\left(a^{\prime}-a\right)^{2}}} \\
\Delta a m q=\frac{a^{\prime}+a}{\sqrt{c^{2}+\left(a^{\prime}-a\right)^{2}}}
\end{gathered}
$$

These integrals may all be found in the tables of Legendre, Traité des Fonctions Elliptiques, Tome II.

This formula, which is an exact one, is very valuable, as it expresses the mutual inductance between two symmetrically placed solenoids in terms of elliptic integrals of the first and second kinds only.

It is shown below to be equivalent to the equation of method III for the case in which $b=b^{\prime}$.

It is to be noticed that it is more general than the formula of method III.

To find the self-inductance of a solenoid, we apply this formula to the case of two identical solenoids identically placed, and compute their mutual inductance. The formula simplifies very materially under these circumstances as

$$
\frac{b-b^{\prime}}{2}=\mathrm{O}=c \text { and } \frac{b+b^{\prime}}{2}=c^{\prime}=b
$$

The term containing the incomplete integrals drops out entirely since it contains the factor $\left(a^{\prime}-a\right)$ which is zero. Putting $2 a=d$ we have

$$
\begin{gathered}
V_{1}=4 \frac{n^{2}}{b^{2}} \pi\left\{\frac{\sqrt{d^{2}+b^{2}}}{3}\left(d^{2}-b^{2}\right) E+\frac{b^{2}}{3} \sqrt{d^{2}+b^{2}} F-\frac{b d^{2} \pi}{4}\right\} \\
V=4 \frac{n^{2}}{b^{2}} \pi \frac{d^{3}}{3} E=4 \frac{n^{2}}{b^{2}} \pi \frac{d^{3}}{3}
\end{gathered}
$$

The term involving $F$ drops out in $V$, since the fraction multiplying it contains in the numerator either $c$, which is zero, or $a^{2}-a^{2}$ which is also zero.

Notice also that the last term of $V$, equation (35), just cancels the first term of equation (33), leaving the following equation for the self-inductance : 


$$
\left.L=\frac{4}{3} \pi \frac{n^{2}}{b^{2}} \mid p\left(d^{2}-b^{2}\right) E+p b^{2} F-d^{3}\right\}
$$

where the letters have the meanings already given.

This formula, as has been said before, is identical with the one deduced in method III, and therefore they afford a check on each other, not only numerically, but theoretically, as showing the correctness of the improved formula of Kirchhoff.

The formula in its complete form was communicated to me by Prof. Antonio Ròiti, of Florence, to whom it was communicated by Professor Kirchhoff in writing.

Professor Ròiti ${ }^{1}$ employed it in his calculation of the mutual inductance of the coils used in his determination of the ohm in absolute value.

\section{METHOD V.}

MUTUAL INDUCTANCE BY MEANS OF A CONVERGING INFINITE SERIES, DEDUCED BY INTEGRATION OF A SERIES IN SPHERICAL HARMONICS, DUE TO MAXWELL.

The self-inductance of an infinitely long solenoid per unit of length, where $n_{1}$ is the number of turns per unit length, is

$$
L=4 \pi n_{1}^{2} S
$$

$S$ being the area of the cross section of the solenoid.

The mutual inductance between two coaxial circular cylindrical solenoids of infinite length per unit of length is

$$
M=4 \pi n_{1} n_{1}^{\prime} S
$$

where $S$ is the area of the smaller section; $n_{1}$ and $n_{1}^{\prime}$ are the number of turns per unit length for the two coils, respectively.

For a coil of finite length we must take into account the demagnetizing effect of the ends. These ends act, as is well known, like the ends of a magnet uniformly polarized axially. Since the ends cause a demagnetizing effect, or in other words a decrease in the induction because the field through one coil, due to unit current in the other, is decreased, it follows that the expression

$$
L=4 \pi n_{1}^{2} S b
$$

${ }^{1}$ Il Nuovo Cimento, vol. 12, page 6o, I882, and vol. 15, page 97, I884.

24353 -No. $\mathrm{x}-\mathrm{O} 6 \mathrm{6}-9$ 
is an upper limit to the value for the self-inductance of a solenoid of length $b$, area $S$ and $n_{1}$ turns per unit of length.

The longer the coil, in comparison with the area of its cross section, the more nearly does this give the true value.

It is interesting to note that, since $S=\pi \alpha^{2}$, the foregoing approximate formula for the self-inductance of a long coil may be written

$$
L=2 \pi a n_{1} \times 2 \pi a n_{1} b
$$

or in words the easy rule:

The self-inductance of a long solenoid is approximately given by multiplying the length of wire in unit length of the coil, by the total length of wire in the coil.

The following demonstration is taken from Maxwell: ${ }^{1}$ In Thomson and Tait's treatise on Natural Philosophy, article 546, Example II, is to be found the following expression for the potentia ${ }^{1}$ of a plane circular magnetic shell, at a point $P(x, y, z)$, in terms of spherical harmonics.

The $P$ 's are those zonal harmonics corresponding to the angle $\theta$ shown in the figure.

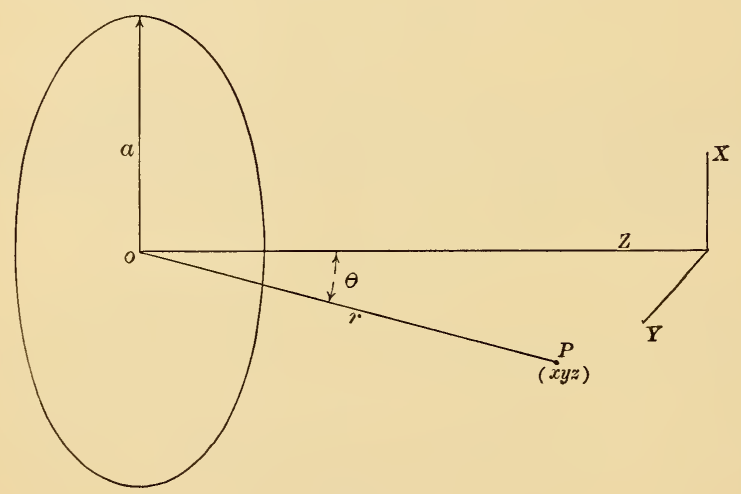

Fig. 13.

$$
\begin{aligned}
V= & 2 \pi\left\{-r P_{1}+a+\frac{I}{2} \frac{r^{2}}{a} P_{2}-\frac{I}{2} \frac{I}{4} \frac{r^{4}}{a^{3}} P_{4}+\frac{I}{2} \frac{I}{4} \frac{3}{6} \frac{r^{6}}{a^{5}}+\ldots\right\} r<a \\
& =2 \pi\left\{\frac{\mathrm{I}}{2} \frac{a^{2}}{r}-\frac{\mathrm{I}}{2} \cdot \frac{\mathrm{I}}{4} \frac{a^{4}}{r^{3}} P_{2}+\frac{\mathrm{I}}{2} \frac{\mathrm{I}}{4} \frac{3}{6} \frac{a^{6}}{r^{5}} P_{4}-\ldots \ldots\right\} r>a
\end{aligned}
$$


If we differentiate the second series with respect to $r$, we shall obtain the radial component of the force. Now multiply by $2 \pi r^{2} d \mu$ and integrate from $\mu=\mathrm{I}$ to $\mu=\frac{z}{\sqrt{z^{2}+A^{2}}}$ where $A$ is the radius of the larger of the two coils. This gives the coefficient of inductance of a single winding of the outer solenoid due to the circular disk which forms the end of the inner solenoid at a distance $z$ from the positive end.

To find it for all the windings integrate from $z=0$ to $z=b$, the length of the solenoids. Multiplying this by $n_{1} n_{1}{ }^{\prime}$ the effect of one end of the inner solenoid is obtained in diminishing the coefficient of mutual inductance as given for the case of infinite length. The result is:

$$
\begin{gathered}
M=4 \pi^{2} n_{1} n_{2} a^{2}(b-2 A a) \text { where } \\
a=\frac{\mathrm{I}}{2} \frac{A+b-r}{A}-\frac{\mathrm{I} \cdot 3}{2 \cdot 4} \cdot \frac{\mathrm{I}}{2 \cdot 3} \frac{a^{2}}{A^{2}}\left(\mathrm{I}-\frac{A^{3}}{r^{3}}\right) \\
+\frac{\mathrm{I} \cdot 3 \cdot 5}{2 \cdot 4 \cdot 6} \frac{\mathrm{I}}{4 \cdot 5 \cdot \frac{a^{4}}{A^{4}}}\left(-\frac{\mathrm{I}}{2}-2 \frac{A^{5}}{r^{5}}+\frac{5}{2} \frac{A^{7}}{r^{7}}\right)+\ldots
\end{gathered}
$$

where $r^{2}=b^{2}+A^{2}$.

It appears then that when the solenoids are not infinitely long, the length $b$ must be diminished by $A a$ at each end.

When the solenoid is quite long compared with its radius

$$
a=\frac{\mathrm{I}}{2}-\frac{\mathrm{I}}{\mathrm{I} 6} \frac{a^{2}}{A^{2}}-\frac{\mathrm{I}}{\mathrm{I} 28} \frac{a^{4}}{A^{4}}+\ldots
$$

In computing self-inductance $a=A$ and $a=0.4297=0.43$ approx. Hence the self-inductance of a solenoid may be computed by the simple formula

$$
L=2 \pi a n \times 2 \pi a n b^{\prime}
$$

Where $b^{\prime}$, the value used in the calculation, is the length $b$ diminished by 0.86 times the radius.

Applying formula $\left(3^{8}\right)$ to a coil of the following dimensions we obtain these results:

$$
\begin{aligned}
\text { radius, } a & =27.09 \mathrm{~cm} \\
\text { length, } b & =44.12 \mathrm{~cm} \\
n & =716 \text { turns. }
\end{aligned}
$$


The inductance found is $0.216_{3}$ henry, whereas the true inductance is 0.2145 henry. The correction to the length in this calculation is I $5.99 \mathrm{cms}$.

The simpler expression (39) gives results to only 30 per cent for this case, but for long coils of length over ten times their diameter it is accurate enough for rough experimental purposes.

It is thus seen that the equation (38) gives results on such a coil as the one described, for example, to about I part in Ioo.

The formula of this method does not converge very rapidly for coils as short as those to which it had to be applied, so that the labor of extending it, while not very great, was thought unwarranted.

\section{METHOD VI.}

\section{MUTUAL INDUCTANCE. RÒITI'S FORMULA.}

Professor Ròiti has kindly communicated to me the following unpublished expansion of Maxwell's formula of method V, which he used in calculating the mutual inductance of two coils used in his determination of the ohm. It has not been found convenient as yet to verify this formula, but it looks very much simpler for numerical calculation than the one just given in method $\mathrm{V}$.

$$
\begin{aligned}
M=4 \pi^{2} a^{2} \frac{{ }^{n}}{b} \cdot \frac{n^{\prime}}{b_{1}}\left\{\rho_{2}-\rho_{1}+\frac{a^{2} A^{2}}{8}\left(\frac{\mathrm{I}}{\rho_{1}{ }^{3}}-\frac{\mathrm{I}}{\rho_{2}{ }^{3}}\right)-\frac{a^{4} A^{4}}{\mathrm{I} 6}\left(\frac{\mathrm{I}}{\rho_{1}{ }^{5}}-\frac{\mathrm{I}}{\rho_{2}{ }^{5}}\right)\right. \\
\left.+\frac{5 a^{4} A^{4}}{64}\left(\frac{\mathrm{I}}{\rho_{1}{ }^{7}}-\frac{\mathrm{I}}{\rho_{2}{ }^{7}}\right)-\cdots\right\}
\end{aligned}
$$

where

$$
\rho_{1}{ }^{2}=\left(\frac{b-b_{1}}{2}\right)^{2}+A^{2}, \quad \rho_{2}{ }^{2}=\left(\frac{b+b_{1}}{2}\right)^{2}+A^{2}
$$

and where

$a$ and $A$ are the internal and external radii, respectively,

$b$ and $b_{1}$ are the respective lengths,

$n$ and $n^{\prime}$ are the respective total numbers of turns.

The longer the coils in comparison with their radii the faster does this series converge. 
7. DATA FOR CALCULATION.

\section{ARBITRARY CORRECTION TO THE LENGTHS.}

The coil lengths as given above (p. IO3) were not used in the calculations. The length of any coil was taken to extend from the center of gravity of the last semicircle of wire on one end to the corresponding point in the last semicircle at the other end. The reasons for this are as follows: To take the length of coil from edge to edge of wire is evidently taking a superior limit to the length, while to take the length to extend from the axis of the last wire on one end to the axis of the last wire on the other is evidently using an inferior limit to the length that should be employed. As for low frequencies the current is almost uniformly distributed throughout the cross section of the conductor, and it is the mutual effect of the

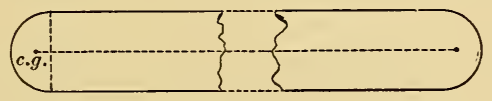

Fig. 14.

current filaments which produces the self-inductance, the assumption made above seemed to the writer to be nearer the truth than either of the above extreme cases.

This correction gave the value $0.0365 \mathrm{~cm}$ to be subtracted from each coil length.

It occurred to the writer that this arbitrary but reasonable assumption could be tested by a reduction to an extreme case. Suppose the coil reduced to one turn, at what distance apart may we consider the current filaments to be concentrated so that the mutual inductance between them will give the actual self-inductance of the one turn? The theory of the logarithmic mean distance says that this distance is given by $0.7788 \times$ radius of the wire, which for this case is 0.0248 $\mathrm{cm}$; but according to the assumption above made this distance would be $2 \times$ radius of the bare wire $-.0365 \mathrm{~cm}=.0269 \mathrm{~cm}$, which is in pretty good agreement with the value 0.0248 derived above.

Or the following argument might be tried. What is the average length of all the infinitely thin current sheets into which the area of Fig. I4, considered as a current sheet with round ends, might be divided? Calculation shows that the average length would be obtained by subtracting $0.0138 \mathrm{~cm}$ from the total length. 
How well does this apply in the limiting case of one turn? The average length of current sheets into which a circle the size of the wire may be divided is $0.0496 \mathrm{~cm}$.

What is the length of the current sheet equivalent to the circle? The theory of the logarithmic mean value says that the circle is equivalent to two filaments at a distance apart of $0.0248 \mathrm{~cm}$; and it also asserts that the current sheet equivalent to this is given by the equation

$$
.0248=b \times 0.223 I
$$

whence $b=\frac{.0248}{.223 \mathrm{I}}=0 . \mathrm{III} \mathrm{cm}$ and the agreement is not nearly so good.

As the whole thing is arbitrary the former assumption has been chosen as preferable to the latter and the lengths corrected accordingly.

Taking account of the thickness of the insulation at both ends, the correction to be subtracted from each coil length is

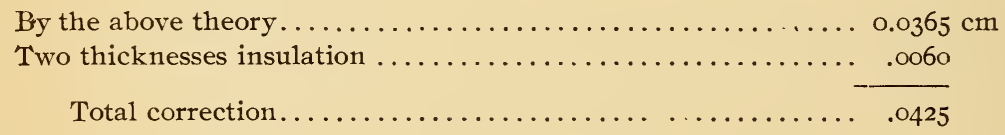

The difference in length in the current sheets calculated on these two assumptions is $0.02 \mathrm{~cm}$, or about I part in 2,000 of the total length. This means about I part in 4,000 difference in the selfinduction.

Should a better value be suggested, the calculated values may be corrected.

The average deviation of the mean of the length measurements considered as measurements of a single invariable length, was for the longest coil only about $0.005 \mathrm{~cm}$, and for the shortest coil 0.003 $\mathrm{cm}$, which is a degree of precision better than I part in 9,000 and I in 4,000 for the two coils, respectively. In other words, the end windings actually deviated from the mean length by only these amounts on the average.

The value of the mean length is of course much more accurately determined than this, as the average of the different measurements represents the true mean length of the coil better than the average deviations of them from the mean length as measured. 
The data used in the calculations is contained in the following table. The lengths of the sections are obtained from those on page ro 3 by subtracting $0.0425 \mathrm{~cm}$, and the diameter is obtained from the value given on page 99 by adding 0.0694 , the thickness of the covered wire.

TABLE II.

Showing the Dimensions of the Several Sections of the Bureau of Standards Inductance Standard.

\begin{tabular}{c|c|c|c}
\hline Coil & Number of turns & Length in cm & Diameter in cm \\
\hline 1 & 221 & 15.2922 & 54.1724 \\
2 & 251 & 17.3140 & 54.1724 \\
3 & 189 & 13.1520 & 54.1724 \\
$1+2+3$ & 661 & 45.8432 & 54.1724 \\
$1+2$ & 472 & 32.6487 & 54.1724 \\
$2+3$ & 440 & 30.5085 & 54.1724 \\
\hline
\end{tabular}

The ohmic resistances of the three coils are approximately as follows:

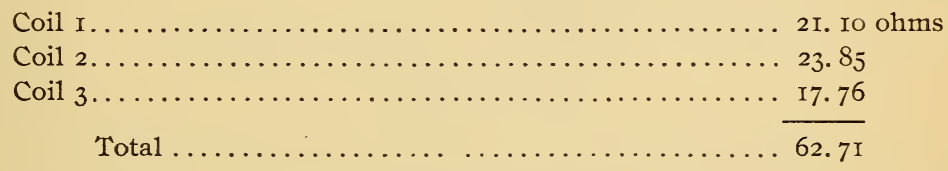

\section{CLARK UNIVERSITY COIL.}

The same general considerations apply to the measurements, calculations, and data of the coil retained by Clark University.

The diameter compared with the standard rod was $0.00125 \mathrm{~cm}$ larger than the mean diameter. The comparison of the rod with the cylinder gave the following result.

Diam. $(\bar{B} .8,6.5)=$ rod + .or $48 \mathrm{~cm}$, with an average deviation of the mean of .ooor I cm, and

$$
\begin{aligned}
\text { mean diam } & =\operatorname{rod}+. \text { or } 48 \mathrm{~cm}-. \text { oor } 3 \mathrm{~cm} \\
& =\operatorname{rod}+. \text { or } 35 \mathrm{~cm} .
\end{aligned}
$$

The cylinder and rod were both at the same temperature, I9:6 C, and as the expansion of marble and steel is practically the same, 
these numbers require no correction to reduce to $20^{\circ}$, so that since the length of rod is $54 \cdot \operatorname{II} 5$ at $20^{\circ} \mathrm{C}$, the mean diameter of the bare cylinder at $20^{\circ}$ is

$$
\text { 54.III } 5 \mathrm{~cm}+0.0135 \mathrm{~cm}=54.1250 \mathrm{~cm}
$$

The diameter of the covered wire was .06I $7 \mathrm{~cm}$

Of the bare wire, $.0602 \mathrm{~cm}$

Twice insulation, .001 $5 \mathrm{~cm}$

The length measurements gave the following results reduced to $20^{\circ} \mathrm{C}$ (marble was at $25^{\circ} \cdot 36 \mathrm{C}$, scale at $26^{\circ}$ ro $\mathrm{C}$ ).

Total coil length at $20^{\circ} \mathrm{C}=44.1548 \mathrm{~cm}, 7 \mathrm{I} 6$ turns. Longer half of coil at $20^{\circ} \mathrm{C}=23.4397 \mathrm{~cm}, 380$ turns.

Shorter half of coil at $20^{\circ} \mathrm{C}=20.7 \mathrm{I} 5^{\mathrm{I}} \mathrm{cm}, 336$ turns.

In the first of these determinations the average deviation of the separate measurements from the mean was 8 parts in 430,000; the remaining two had deviations of about 8 parts in 200,000.

Correcting these lengths as explained above, $0.0369 \mathrm{~cm}$ is to be subtracted from each coil length.

The data as used for calculation are here tabulated:

TABLE III.

Showing the Dimensions of the Sections of the Clark Standard of Inductance.

\begin{tabular}{l|c|c|c|c}
\hline Coil & $\begin{array}{c}\text { Number of } \\
\text { turns }\end{array}$ & $\begin{array}{c}\text { Length coils from edge } \\
\text { to edge }\end{array}$ & $\begin{array}{c}\text { Corrected for calcula- } \\
\text { tion }\end{array}$ & Diameter \\
\hline A & 380 & $23.4397 \mathrm{~cm}$ & $23.4028 \mathrm{~cm}$ & $54.1867 \mathrm{~cm}$ \\
$\mathrm{~B}$ & 336 & 20.7151 & 20.6783 & 54.1867 \\
$\mathrm{~A}+\mathrm{B}$ & 716 & 44.1548 & 44.1179 & 54.1867 \\
\hline
\end{tabular}


Using these data the following values of self-inductance were obtained for the three coils, in henrys:

\section{TABLE IV.}

Showing the Values of Inductances of the Separate Sections, Computed by Three Different Formulae.

\begin{tabular}{l|l|l|l}
\hline \multicolumn{1}{c|}{ Coil } & \multicolumn{1}{|c|}{ Method I } & \multicolumn{1}{|c}{ Method II } & \multicolumn{1}{|c}{ Method III } \\
\cline { 2 - 3 } $\mathrm{A}_{1+2}$ & 0.0728935 henry & 0.0728924 henry & 0.0728932 henry \\
$\mathrm{B}_{1+2}$ & 0.0876479 & 0.0876483 & 0.0876488 \\
$(\mathrm{~A}+\mathrm{B})_{1+2}$ & $0.216234^{\mathrm{I}}$ & 0.216240 & 0.216246 \\
\hline
\end{tabular}

I This value is about 4 parts in 100,000 too small, as is expected in the use of the logarithmic formula.

The ohmic resistances of the windings are given below:

$$
\begin{array}{cc}
\text { Coil } A_{1} & \text { 2I.92 ohms } \\
\text { Coil } A_{2} & 2 \mathrm{I} .9 \mathrm{I} \\
\text { Coil } B_{1} & \text { I9.83 } \\
\text { Coil } B_{2} & \text { I9.33 } \\
\frac{\text { Total }}{(A+B)_{1+2}} & \frac{82.99}{}
\end{array}
$$

The calculations were made by seven-place logarithms. Three formulæ were at first employed, which for convenience are given below with references to places where they occur in the text. However, as two of these formulæ (II and III) were found to be identical, the later calculations were made with but the first two.

In the following formulæ,

$$
\begin{aligned}
& d=\text { diameter of the winding, } \\
& a=\text { radius of the winding, } \\
& b=\text { length of the winding, } \\
& n=\text { whole number of turns of wire, } \\
& N=\log _{e} \frac{8 a}{b}
\end{aligned}
$$


I. $L=4 \pi a n^{2}\left\{\left(N-\frac{\mathrm{I}}{2}\right)+\frac{b^{2}}{32 a^{2}}\left(N+\frac{\mathrm{I}}{4}\right)-\frac{\mathrm{I}}{\mathrm{IO} 24} \frac{b^{4}}{a^{4}}\left(N-\frac{2}{3}\right)\right.$ $\left.+\frac{\text { IO }}{\text { I } 3 \text { IO } 72} \frac{b^{6}}{a^{6}}\left(N-\frac{\text { IO9 }}{\text { I } 20}\right)-\frac{35}{4 \text { I } 94304} \frac{b^{8}}{a^{8}}\left(N-\frac{43 \mathrm{I}}{420}\right)\right\}$ See page II 3.

II. $L=\frac{4}{3} \pi \frac{n^{2}}{b^{2}}\left\{p\left(d^{2}-b^{2}\right) E+p b^{2} F-d^{3}\right\} \quad$ See page I 24 .

In formula II, $p^{2}=d^{2}+b^{2}$ and the complete elliptic integrals $E$ and $F$ are to the modulus $k^{2}=\frac{d^{2}}{d^{2}+b^{2}}=\frac{d^{2}}{p^{2}}$

III. $L=\frac{4}{3} \pi d^{2} \frac{n^{2}}{b^{2}}\left\{\frac{3 b^{2}}{p k^{2}}(F-E)-\frac{p}{k^{2}}\left[2\left(\mathrm{I}-k^{2}\right) F-\left(2-k^{2}\right) E\right]-\alpha\right\}$

See page I 23 .

A sample calculation by means of I and II is here given. The labor is much diminished by carefully planning these calculations and using the correct number of significant figures. The values of the logarithms of all the constants of the formulæ are also given. 


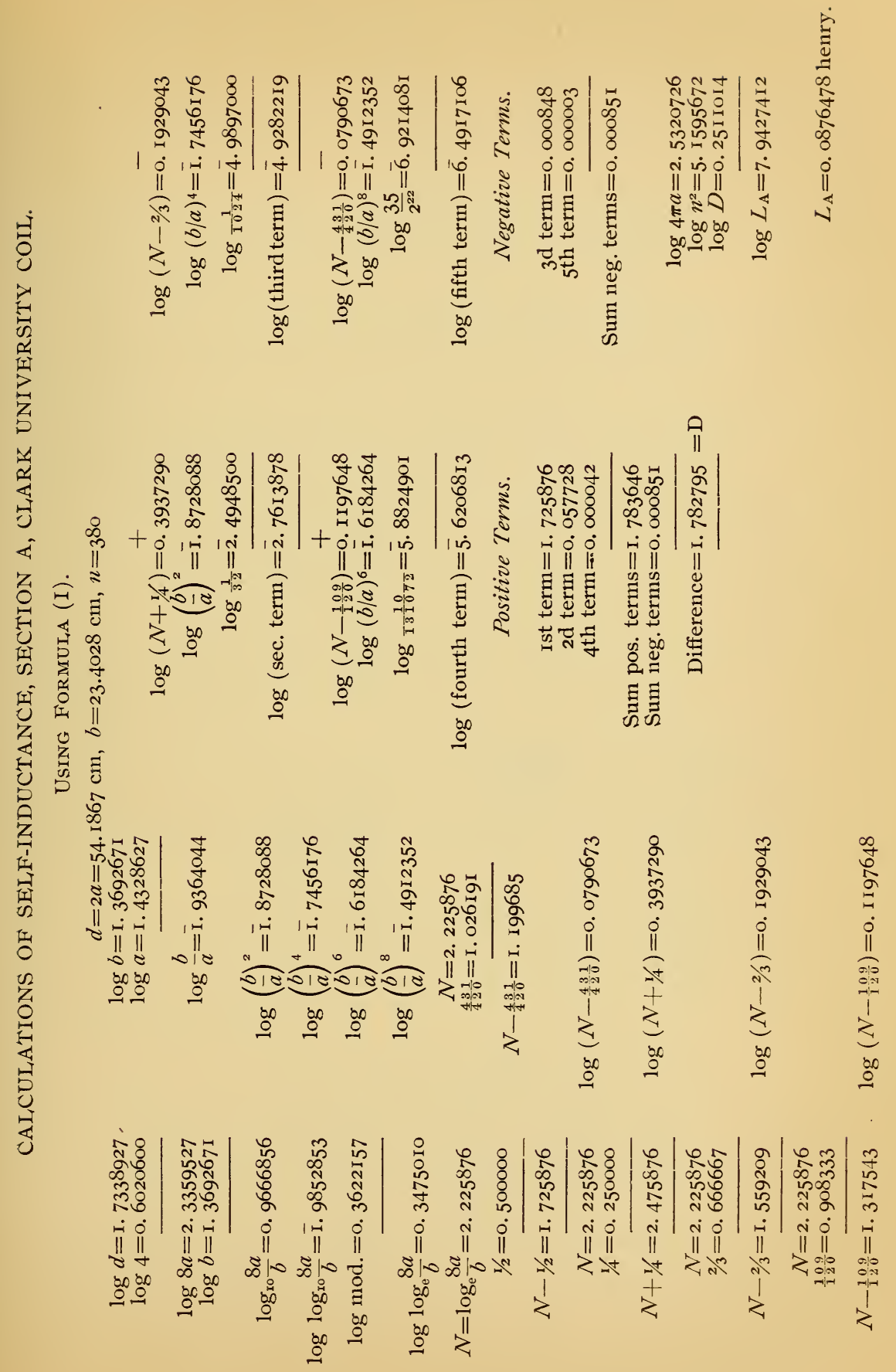




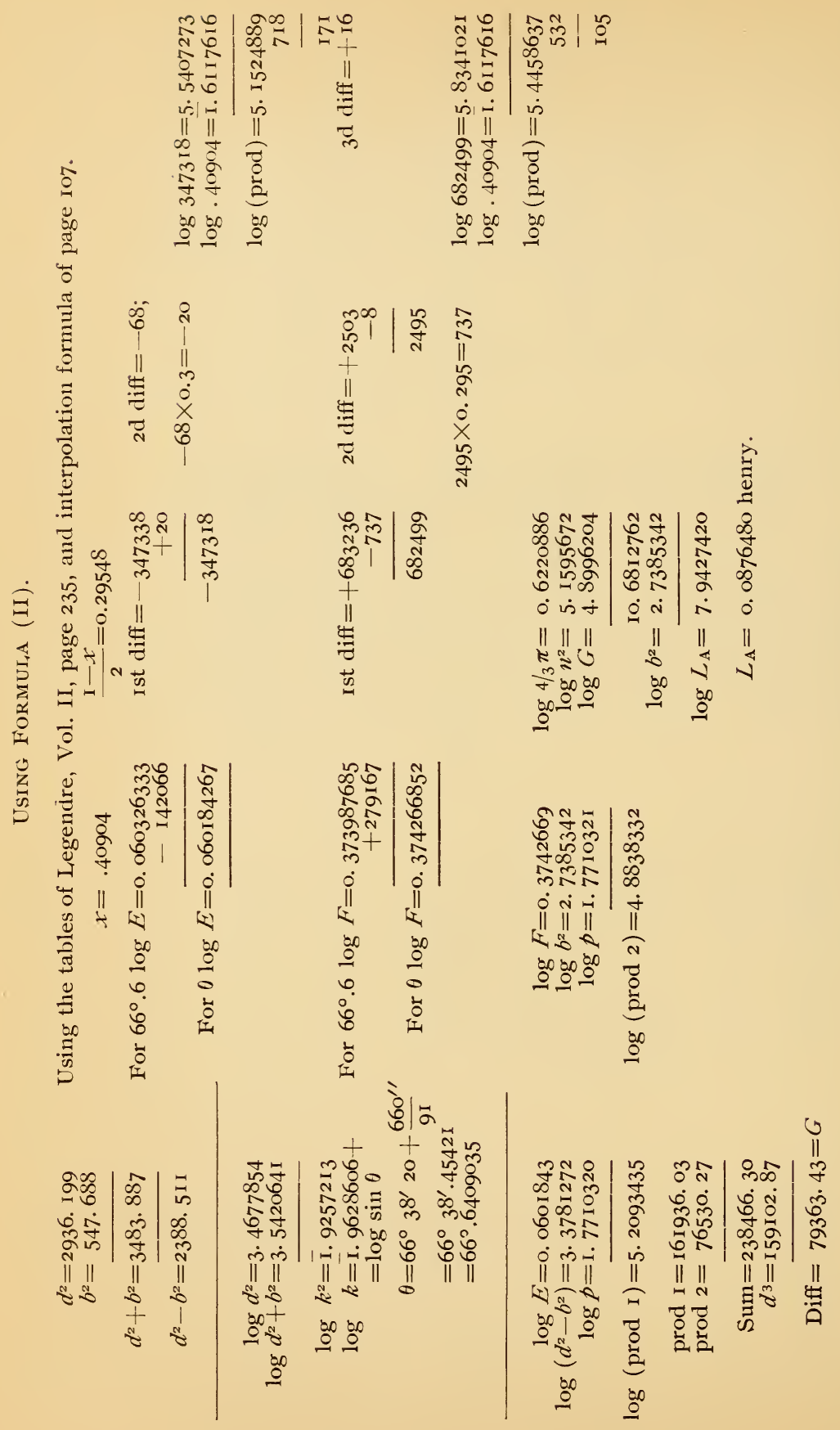




\section{TEMPERATURE COEFFICIENT OF THE INDUCTANCE STANDARDS.}

In very accurate work variation of temperature may have a decided influence. The only way it can affect the self-inductance of the standard coil is by a change in the length and the mean radius.

These vary, for reasons stated above (page ro4), with the same temperature coefficient as that of marble, namely, about o.oooor per degree centigrade.

It is evident that these changes in dimensions may be allowed for and the temperature coefficient of inductance computed for any given coil.

To find the magnitude of this coefficient the following calculations were undertaken on coil $\mathrm{A}$, of the Clark standards.

The self-inductance was calculated, making a change of o.I per cent in the length but keeping the radius constant, and a coefficient $\frac{\partial L}{\partial b}$ was thus determined. Then by making an equal change in the radius and keeping the length constant $\frac{\partial L}{\partial a}$ was determined.

Then evidently,

$$
d L=\frac{\partial L}{\partial a} d a+\frac{\partial L}{\partial b} d b
$$

for simultaneous changes in $a$ and $b$ as long as they are small.

The results were that

.I per cent increase in $a$ produced . I 52 per cent increase in $L$ .I per cent increase in $b$ produced .052 per cent decrease in $L$

This means that

$$
\begin{aligned}
& \frac{\partial L}{\partial a}=.0049 \text { r henrys per } \mathrm{cm} \\
& \frac{\partial L}{\partial b}=-.00194 \text { henrys per } \mathrm{cm}
\end{aligned}
$$

This shows that the length measurements on the radii should be about 2.5 times as precise as those on the length to give the same relative error in the computations. 
A change of $I$ in $I, 000$ in both $a$ and $b$ would produce a joint error in $L$ of about $\mathrm{I}$ in $\mathrm{I}, \mathrm{OoO}$. So that the inductance temperature coefficient of this particular coil is about.+ oooor per $\mathrm{I}^{\circ} \mathrm{C}$, as the linear temperature coefficient is about + .oooor per $\mathrm{I}^{\circ} \mathrm{C}$. The temperature coefficients of the other coils are approximately of this same order. A reference to the table below will show just how the coefficient $\frac{\partial L}{\partial a}$ varies for coils of different lengths. The coefficients $\frac{\partial L}{\partial b}$ have not as yet been calculated.

$$
\text { Values of } \frac{\frac{\partial L}{L}}{\frac{\partial}{a}} \text {. I\% change in } a \text { produces } x \% \text { change in } L \text {. }
$$

10. ON THE DISTRIBUTED CAPACITY OF A COIL.

Distributed capacity must not be confounded with the ordinary electrostatic capacity of an insulated conductor. A coil of wire considered as an insulated conductor, has, of course, a definite electrostatic capacity, which is numerically measured by the quantity of electricity necessary to raise the coil to unit potential.

To explain the idea of distributed capacity, consider a coil of a single layer in which an electrical charge is oscillating. The period of this oscillation has a value given by the formula

$$
T=2 \pi \sqrt{L_{\mathrm{m}} C_{\mathrm{m}}}
$$

where $T$ is the period of a complete oscillation to and fro in seconds; $L_{\mathrm{m}}$ the self-inductance of the coil for high frequency currents in henrys and $C_{\mathrm{m}}$ the distributed capacity of the coil in farads. If $T$ and $L_{\mathrm{m}}$ are known, then the value of $C_{\mathrm{m}}$ may be computed by the formula. This capacity, $C_{\mathrm{m}}$, arises in the following manner:

On account of the rapidity of the oscillations, the distribution of the moving charge is not uniform; this causes different portions of the 
same coil to be at different potentials for the time being, so that two adjacent turns being at different potentials, a chafge will accumulate on them, for the instant, just as if they were insulated conductors in the same relative position and charged to the same difference of potential. Strictly speaking, every portion of the wire would be at a different potential from every other portion, and to be exact one should speak of adjacent portions of adjacent turns. The distribution of the potential upon the wires is connected with the period, so that it follows that the distributed capacity is some function of the period. Such conditions give rise to a true electrostatic capacity which helps determine the frequency of the oscillations. The calculation of the value of this capacity is evidently a very complex matter. It would be much larger for coils of many layers than for a coil of a single layer with the same number of turns.

Paul Drude, ${ }^{1}$ in a most instructive and valuable paper, makes an approximate theoretical calculation, thoroughly checked by experiment, upon the value of the wave length $\lambda$ for the fundamental oscillation in a coil of a single layer. By means of his results, the fundamental periods for the two coils here considered may be calculated. The value of this capacity for single-layer coils is very small. Lodge and Glazebrook ${ }^{2}$ estimated the value of the distributed capacity of the coil they used in their experiments to be but a small fraction ( 2 or 3 per cent) of the total value of the capacity they used, and their coil was one of many layers in which one would expect this capacity to be large.

Since $C_{\mathrm{e}}$, the capacity in the electrostatic system is $\frac{\mathrm{I}}{v^{2}}$ times $C_{\mathrm{m}}$, the same capacity in the electro-magnetic system, where

it follows that we may write

$$
v=3 \times \mathrm{IO}^{10} \mathrm{~cm} \mathrm{sec}^{-1} \text {, }
$$

$$
T=\frac{\lambda}{v}=2 \pi \sqrt{L_{\mathrm{m}} C_{\mathrm{m}}}=2 \pi \sqrt{L_{\mathrm{m}} \frac{C_{\mathrm{e}}}{v^{2}}}
$$

and therefore

$$
\frac{\lambda}{2}=\pi \sqrt{L_{\mathrm{m}} C_{\mathrm{e}}}
$$

In Drude's paper (pp.32I-323) we may obtain the value of $\lambda_{2}$ for any coil by the following formula: $\frac{1}{2} \lambda=f$. $l$, where $l$ is the total 
length of wire in the coil, and where $f$ is a function to be taken from the table, and depending for a given wire, wound in a given manner, upon the ratio of the length of the coil to its diameter. Making these calculations, the following table is obtained:

\section{TABLE V.}

Showing the Approximate Values of the Distributed Capacities of the Various Sections of the Two Standard Coils.

[The values in the last column are probably correct to about 5 per cent. See also F. Dolezalek, Wied. Ann. 12, 1. I142. 1903.]

\begin{tabular}{|c|c|c|c|c|c|c|c|c|}
\hline Coil & $\begin{array}{l}\text { Length } \\
\text { of coil } \\
\text { b cm }\end{array}$ & $\begin{array}{l}\text { Num- } \\
\text { ber } \\
\text { turns }\end{array}$ & $\mathrm{b} / 2 \mathrm{r}$ & $\mathrm{f}$ & $\begin{array}{l}\text { Length of } \\
\text { wire in } \mathrm{cm}\end{array}$ & $\frac{1}{2} \lambda$ in $\mathrm{cm}$ & $\begin{array}{c}L_{m} \text { in } \\
\text { henrys }\end{array}$ & $\begin{array}{l}\text { Distrib. } \\
\text { Cap. in } \\
\mathrm{cm}\end{array}$ \\
\hline $1+2+3$ & 45.84 & 661 & 0.847 & 1.43 & $1.125 \times 10^{5}$ & $1.63 \times 10^{5}$ & 0.180 & 14.8 \\
\hline $1+2$ & 32.65 & 472 & .604 & 1.67 & .803 & 1.34 " & .113 & 15.9 \\
\hline $2+3$ & 30.51 & 440 & .563 & 1.75 & .750 & 1.31 & .102 & 16.9 \\
\hline 2 & 17.31 & 251 & .321 & 2.08 & .427 ، & .888 ، & .0442 & 17.7 \\
\hline 1 & 15.29 & 221 & .282 & 2.12 & .376 " & .800 & .0362 & 17.8 \\
\hline 3 & 13.15 & 189 & .243 & 2.13 & $.322 \quad 6$ & .708 & .0283 & 17.9 \\
\hline$A+B$ & 44.12 & 716 & .814 & 1.47 & $1.240 \times 10^{5}$ & $1.80 \times 10^{5}$ & .216 & 15.0 \\
\hline A & 23.40 & 380 & .451 & 1.86 & .647 “ & 1.20 " & .0876 & 28.8 \\
\hline B & 20.68 & 336 & .382 & 1.95 & .572 & 1.12 & .0729 & 23.4 \\
\hline
\end{tabular}

\section{EFFECT OF DEVIATIONS FROM THE MEAN RADIUS.}

Another point of interest in the calculation of the self-inductance of so-called circular coils with any cross section, is the influence of the deviations from circularity.

Max Wien ${ }^{1}$ has made the following experiment. The self-inductance of a circular coil was carefully measured, the coil was then strained into an ellipse whose axes were in the ratio of two to three. The self-inductance changed from $75 \mathrm{I} .5$ to 730.4 arbitrary units. That such a large distortion should produce such a small variation is surprising, and proves that small variations from true circularity affect the self-inductance but little. In other words, a coil of elliptical shape, or even of an irregular shape, if the ellipticity or irregularities were small, would have almost exactly the same self- 
inductance as a truly circular coil, as long as they had the same mean radius.

The mathematics of such a case would be formidable, but the results of the experiments of Max Wien show that it is not worth while to attempt any theoretical solution of the problem.

It can be shown also ${ }^{1}$ that if the dimensions of the cross section of a coil are small in comparison with the radius, it makes but very little difference what the shape of the cross section is, as long as it is of constant area. That is, a coil with the same cross section has very closely the same self-inductance as a coil of the same mean radius, but whose cross section is a circle or a polygon of the same area.

Frölich ${ }^{2}$ has recently constructed a standard of self-inductance consisting of a marble ring of rectangular cross section closely wound with wire. It is wound so that every turn lies in a plane passing through the axis of the ring. The self-inductance of such a coil is well known to be

$$
L=4 n^{2} a \log \frac{R+a}{R-a}
$$

where $2 a$ is the side of the cross section, and $R$ is the mean radius of the ring.

It would seem that such a shape would offer great difficulties in turning accurately. It certainly requires a large number of measurements of inside and outside diameters, and of the width, both inside and outside. The wire can not possibly be equally spaced on the outside and inside, and the turning of the sharp corners, assumed in the theory, is only approximately attained in practice. The wound coil is liable to injury, as its weight, which is considerable, must always bear on the wires.

It would seem that such a coil, although possible to construct, as the fine work of Frölich has proven, is not the best form for a primary standard of self-inductance.

NOTE-In conclusion the writer wishes to acknowledge his indebtedness to Clark University for the opportunity to carry out the research and for the facilities afforded, and to Prof. A. G. Webster for his many fertile suggestions, his infinite patience, and his support and encouragement throughout the investigation.

${ }^{1}$ Statement of Lord Rayleigh, loc. cit. Coll. Papers, Vol. II, p. I5.

${ }^{2}$ Frölich: Ann. der Phy. u. Ch. 63, I897, p. I42.

24353-No. I-O6-IO 